\title{
Transcriptomic buffering of cryptic genetic variation contributes to meningococcal virulence
}

\author{
Biju Joseph Ampattu ${ }^{1 \dagger}$, Laura Hagmann ${ }^{1 \dagger}$, Chunguang Liang ${ }^{2}$, Marcus Dittrich ${ }^{2,3}$, Andreas Schlüter ${ }^{4}$, Jochen Blom ${ }^{5}$, \\ Elizaveta Krol ${ }^{6}$, Alexander Goesmann ${ }^{5}$, Anke Becker ${ }^{6}$, Thomas Dandekar ${ }^{2}$, Tobias Müller ${ }^{2}$ and Christoph Schoen ${ }^{*^{*}}$ (D)
}

\begin{abstract}
Background: Commensal bacteria like Neisseria meningitidis sometimes cause serious disease. However, genomic comparison of hyperinvasive and apathogenic lineages did not reveal unambiguous hints towards indispensable virulence factors. Here, in a systems biological approach we compared gene expression of the invasive strain MC58 and the carriage strain a522 under different ex vivo conditions mimicking commensal and virulence compartments to assess the strain-specific impact of gene regulation on meningococcal virulence.
\end{abstract}

Results: Despite indistinguishable ex vivo phenotypes, both strains differed in the expression of over 500 genes under infection mimicking conditions. These differences comprised in particular metabolic and information processing genes as well as genes known to be involved in host-damage such as the nitrite reductase and numerous LOS biosynthesis genes. A model based analysis of the transcriptomic differences in human blood suggested ensuing metabolic flux differences in energy, glutamine and cysteine metabolic pathways along with differences in the activation of the stringent response in both strains. In support of the computational findings, experimental analyses revealed differences in cysteine and glutamine auxotrophy in both strains as well as a strain and condition dependent essentiality of the (p)ppGpp synthetase gene relA and of a short non-coding AT-rich repeat element in its promoter region.

Conclusions: Our data suggest that meningococcal virulence is linked to transcriptional buffering of cryptic genetic variation in metabolic genes including global stress responses. They further highlight the role of regulatory elements for bacterial virulence and the limitations of model strain approaches when studying such genetically diverse species as N. meningitidis.

Keywords: Neisseria meningitidis, Virulence, Regulatory evolution, Systems biology, Metabolism, Cryptic genetic variation, Stringent response, MITE, RelA

\section{Background}

The human body is home to a vast number of different bacterial species, and the overwhelming complexity of the human microbiome has only very recently been fully uncovered [1]. Although the majority of these colonizing bacteria seem to be harmless or even beneficial commensals, some have long been known to be Janus-faced, and Neisseria meningitidis is a particularly prominent

\footnotetext{
* Correspondence: cschoen@hygiene.uni-wuerzburg.de

${ }^{\dagger}$ Equal contributors

${ }^{1}$ Institute for Hygiene and Microbiology, Joseph-Schneider-Straße 2,

University of Würzburg, 97080 Würzburg, Germany

Full list of author information is available at the end of the article
}

example in this respect. On the one hand, this $\beta$ proteobacterium is an exclusively human-adapted commensal that is carried in the nasopharynx of about $20 \%$ of the healthy population [2]. On the other hand, $N$. meningitidis is also a ferocious pathogen that can cause life-threatening invasive meningococcal disease (IMD), and "no other infection so quickly slays" [3]. After crossing the mucosal barrier and entering the bloodstream, meningococci can cause septicemia, and by crossing the blood-brain barrier and multiplying in the cerebrospinal fluid (CSF) also acute bacterial meningitis, both often within less than $24 \mathrm{~h}$ [4]. 
In many commensal pathogens like Escherichia coli, often the only difference between a pathogenic and a non-pathogenic strain is a small set of so called virulence genes [5]. By definition, a virulence gene is a gene whose loss specifically impairs virulence but not viability in rich media and which should be associated exclusively with pathogenic but not with non-pathogenic strains of a species [6]. However, with respect to gene content meningococcal strains isolated from healthy carriers and IMD patients are almost indistinguishable [7], and many of the so called meningococcal virulence genes have also been found in purely commensal neisserial species [8]. The analysis of meningococcal population genetic structure by multilocus sequence typing (MLST) demonstrated that disease-causing meningococci do belong to particular groups of related sequence types (STs), termed clonal complexes (CCs), which are overrepresented in disease isolates relative to their carriage prevalences and are responsible for most disease [2]. Accordingly, these data indicate that the propensity to cause invasive disease is somehow associated with the genetic make-up of hyperinvasive lineages. Experimental observations along with epidemiological models further indicate that genetic differences in metabolic genes might have a central role in the observed virulence differences among different lineages in a yet to define manner $[9,10]$.

Alongside the well-established significance of gene content variation in creating genetic diversity in the bacterial world, regulatory evolution is increasingly acknowledged to substantially contribute to this diversity [11]. Mutations affecting gene expression regulation encompass differences in the coding sequences of transcription factors (TF) acting in trans and thus affecting the expression of entire regulons [12, 13], as well as sequence differences in the regulatory regions acting in cis on the expression of downstream genes (e.g. [14]). By acquiring functionally divergent homologous promoter regions through horizontal transfer bacterial genes were shown to rapidly shift between multiple regulatory modes affecting, for example, up to $15 \%$ of the meningococcal core genome [15]. In addition, also mutations in metabolic genes can indirectly cause compensatory changes in gene expression regulation of other housekeeping genes to maintain cellular homeostasis. The ensuing differential regulation of conserved genes can mediate phenotypic traits that distinguish closely related bacterial species [16] or even strains of the same species [17]. In consequence, also the expression of a virulenceassociated gene could be epistatic and thus depend on the genetic background of the respective strain (genegene interaction, $G \times$ G) [18] and/or the environment (gene-environment interaction, G x E) [19]. Given the high genetic diversity of $N$. meningitidis [2], a virulence gene candidate should consequently be differently expressed between an invasive and a commensal strain under disease mimicking conditions but not under conditions mimicking the commensal state. In addition, although the correlation between when genes are important for fitness and when those genes are upregulated was shown to be small [20], the fitness of a knock-out strain should differ between an invasive and a commensal strain $(G \times G)$ under conditions mimicking invasive infection $(\mathrm{G} \times \mathrm{E})$.

The strict tropism of $N$. meningitidis for humans has so far impeded the development of a suitable animal model to analyze the course of meningococcal infection in vivo, and therefore alternative experimental approaches such as ex vivo models have been established to study meningococcal infection biology. For example, human whole blood served as an ex vivo model to analyze how meningococci regulate gene expression to permit survival in human bloodstream during septicemia $[21,22]$. Likewise, meningococcal resistance to human complement was studied in an ex vivo model using human CSF [23], and human saliva has already been used to study ex vivo the transcriptional response which enables meningococci to adapt to this relevant host niche [24]. However, most of these ex vivo studies analyzed gene expression only under a single condition and/or used only a single strain from a hyperinvasive lineage. Consequently, our knowledge about how this commensal pathogen adapts during the transition from colonization to an invasive infection is still very limited, and nothing is known so far about gene expression or phenotypic variability between carriage and hyperinvasive strains in conditions mimicking invasive infection. In a systems biological approach we used different ex vivo conditions as environmental perturbation and natural genetic variation as genetic perturbation of the meningococcal gene expression network and considered gene expression as quantitative intermediate phenotype $[25,26]$. Based on prior population genetic information we selected two genetically related meningococcal serogroup B strains from the same phylogenetic clade PC32/269 [27, 28] with yet markedly different epidemiology (Table 1 and Additional file 1: Figure S1) [2]. Strain MC58 belonging to the hyperinvasive ST-32 CC was chosen as a reference as this strain has already served as a model system to experimentally study meningococcal infection biology in vitro and a large body of transcriptomic data is thus available [21, 22, 29-34]. The carriage strain $\alpha 522$ belongs to the carriage ST-35 CC which is a four locus variant of the ST-32 CC sharing about $96 \%$ of its genes with strain MC58 [28]. We combined phenotypic, genomic and transcriptomic comparisons with mutagenesis studies to seek genetic variants that influence meningococcal gene expression in human saliva, whole blood and CSF mimicking commensal and 
Table 1 Strains used for ex vivo transcriptome comparisons

\begin{tabular}{|c|c|c|}
\hline & a522 & MC58 \\
\hline \multicolumn{3}{|l|}{ Genome characteristics } \\
\hline GenBank accession number & $\begin{array}{l}\text { FR845693 to } \\
\text { FR845718 }\end{array}$ & AE002098 \\
\hline No. of contigs in final assembly & 21 & 1 \\
\hline Average single base coverage & 79-fold & 8.4-fold \\
\hline Genome size (bp) & $\geq 2,074,170$ & $2,272,360$ \\
\hline GC content (\%) & $51.78 \%$ & $51.53 \%$ \\
\hline $\begin{array}{l}\text { Predicted number of coding } \\
\text { sequences }\end{array}$ & $\geq 1985$ & 2063 \\
\hline Reference & This work & $\begin{array}{l}\text { Tettelin et al. } \\
\text { (2000) [123] }\end{array}$ \\
\hline \multicolumn{3}{|l|}{ Molecular epidemiology } \\
\hline Source & Carrier & Patient \\
\hline Country and year of isolation & Germany 2000 & $\begin{array}{l}\text { United Kingdom } \\
1983\end{array}$ \\
\hline Sequence type & ST-35 & ST-74 \\
\hline Clonal complex (CC) & ST-35 & ST-32 \\
\hline Phylogenetic clade (PC) ${ }^{(a)}$ & PC32/269 & PC32/269 \\
\hline Frequency of $C C$ in carriers ${ }^{(b)}$ & $5.47 \%$ & $4.99 \%$ \\
\hline Disease/carriage ratio ${ }^{(c)}$ & 0.5 & 3.5 \\
\hline Reference & $\begin{array}{l}\text { Claus et al. } \\
\text { (2005) [100] }\end{array}$ & $\begin{array}{l}\text { McGuiness et al. } \\
\text { (1991) [101] }\end{array}$ \\
\hline \multicolumn{3}{|l|}{ Phenotypic characterization } \\
\hline Serum resistance $(\%)^{(d)}$ & $117.7 \pm 23.8$ & $116.3 \pm 15.7$ \\
\hline \multicolumn{3}{|l|}{ Adhesion to epithelial cells ${ }^{(\mathrm{e})}$} \\
\hline FaDu cells (\%) & $10.7 \pm 7.4$ & $14.5 \pm 8.5$ \\
\hline Detroit562 cells (\%) & $8.9 \pm 1.8$ & $17.1 \pm 5.3$ \\
\hline \multicolumn{3}{|l|}{ Invasion of epithelial cells ${ }^{(e)}$} \\
\hline FaDu cells (\%) & $0.0008 \pm 0.0001$ & $0.0020 \pm 0.0011$ \\
\hline Detroit562 cells (\%) & $0.0011 \pm 0.0004$ & $0.0016 \pm 0.0007$ \\
\hline \multicolumn{3}{|l|}{ In vitro logarithmic growth rates ${ }^{(t)}$} \\
\hline Rich medium $(\mathrm{PPM}+)(1 / \mathrm{h})$ & $0.46 \pm 0.01$ & $0.47 \pm 0.01$ \\
\hline Minimal medium (MMM) (1/h) & $0.06 \pm 0.01$ & $0.52 \pm 0.02$ \\
\hline \multicolumn{3}{|l|}{ Ex vivo growth rates ${ }^{(g)}$} \\
\hline Saliva (1/min) & $-0.041 \pm 0.003$ & $-0.043 \pm 0.003$ \\
\hline Blood (1/min) & $0.027 \pm 0.004$ & $0.023 \pm 0.002$ \\
\hline $\operatorname{CSF}(1 / \mathrm{min})$ & $0.010 \pm 0.002$ & $0.018 \pm 0.003$ \\
\hline
\end{tabular}

(a) According to ref. [27, 28]

(b) According to ref. [100]

(c) According to ref. [2]

(d) Ratio in percent of viable bacteria after incubation for $30 \mathrm{~min}$ in the presence of $10 \%$ human serum and viable bacteria incubated without serum. Given are the average and standard deviation from four independent experiments with pooled human serum

(e) Ratio in percent of adherent and invasive bacteria, respectively, to total bacteria. Given are the average and standard deviation from at least four independent experiments

(f) Given are the mean and standard deviation of the logarithmic growth rate $k$ according to $\log \left(O D_{600}(t) / O D_{600}(0)\right)=k t$ for $t \in[1 \mathrm{~h}, 4 \mathrm{~h}]$ as depicted in Fig. 5 using linear regression $\left(R_{\text {in vitro }}^{2}=0.96 \pm 0.07, p_{\text {in vitro }}=0.013 \pm 0.026\right)$

(g) Given are the mean and standard deviation of the growth rate $k$ according to $\log (N(t) / N(0))=k t$ for $t \in[0 \mathrm{~min}, 120 \mathrm{~min}]$ as depicted in Fig. 5 using linear regression $\left(R_{\mathrm{ex} \text { vivo }}^{2}=0.95 \pm 0.05, p_{\mathrm{ex} \text { vivo }}=0.018 \pm 0.016\right)$ virulence compartments, respectively. Gene expression was analyzed in a strain- and condition-dependent manner with particular emphasis on virulence-associated genes and genes involved in gene expression regulation. The combined data show that transcriptomic buffering of cryptic genetic variation, which is the genetic variation present in the meningococcal population that is not phenotypically expressed under commensal conditions but visible upon environmental or genetic perturbations such as growth in human blood [35, 36], contributes to the regulatory evolution of meningococcal virulence. We further demonstrate that it is likely affected by the differential presence of a short, non-coding inverted-repeat transposable-element in the promoter region of relA encoding the guanosine 3'-(tri)diphosphate 5-'diphosphate ((p)ppGpp) synthetase of the stringent response pathway.

\section{Results}

MC58 and a522 have similar gene content including most genes invovled in host interactions but with function-

\section{dependent sequence variation among orthologs}

In order to comprehensively analyze genetic differences between both strains we generated a draft sequence of the $\alpha 522$ genome for comparative genome expression analyses (Table 1, Additional file 1: Figure S2A). The common genomic backbone of both strains comprises $1.93 \mathrm{Mbp}$ and encodes 1757 orthologous proteins with an average BLASTP bit score ratio (BSRP) of 0.958 (95\%-confidence interval $(\mathrm{CI})=[0.513,1.000])$, corresponding to an average amino acid identity of $99.4 \%$ $(95 \%-C I=[81.6 \%, 100 \%])$. Notably, there was a significant variation of the BSRPs of orthologous proteins with respect to the COG functional category [37] (KruskalWallis rank sum test, $p<0.05$ ) (Additional file 1: Figure S2B). The 10\% most divergent orthologous genes (BSRP $<0.933, n=177)$ were significantly enriched for genes involved in cell motility (COG $\mathrm{N}$, odds ratio $(\mathrm{OR})=3.8$, false discovery rate $(F D R)=0.031$, Fisher's exact test with Benjamini-Hochberg multiple testing correction) as well as secretion and transport (COG $\mathrm{U}, \mathrm{OR}=2.6, \mathrm{FDR}<$ 0.05). The latter included numerous surface antigens involved in host interactions such as the major type IV pilus subunit protein PilE, the major outer membrane proteins PorA and PorB, the autotransporters App (NMB1985) and NalP (NMB1969), as well as proteins involved in iron acquisition like the transferrin-binding protein B and the lactoferrin-binding protein B. Compared to the $10 \%$ most divergent orthologous genes, identical genes $(n=825)$ were significantly enriched for genes involved in energy production and conversion (COG $\mathrm{C}, \mathrm{OR}=6.9, \mathrm{FDR}<0.01$ ), carbohydrate transport and metabolism (COG G, OR $>1.6$, FDR $<0.05$ ), amino acid biosynthesis (COG E, OR $=1.7, \mathrm{FDR}<0.01$ ) and 
translation, ribosomal structure and biogenesis (COG J, $\mathrm{OR}=5.3, \mathrm{FDR}<0.001$ ) (see Additional file 2: S1). Of the 135 genes coding for putative virulence factors or involved in meningococcal host interactions in strain MC58 (compiled from ref. [21, 38-40], see Additional file 2: S1) only 8 are missing in strain $\alpha 522$, and strain $\alpha 522$ lacks in particular large parts of the islands of horizontal transfer B and C that code for a two-partner secretion system involved in host cell adhesion [41] (Additional file 1: Figure S2A). It further lacks almost the entire repeat-in-toxin island 1 encoding FrpA/C-like proteins which induce high levels of serum antibodies during invasive disease in humans [42]. In addition, downstream of $g \ln B$ encoding the signal-transducing nitrogen regulatory protein PII strain $\alpha 522$ also lacks $n a d A$ which codes for a minor adhesin that was found to promote bacterial adhesion to and penetration into human epithelial cells in vitro [43]. MC58 further harbors a $30 \mathrm{~kb}$ duplication spanning 37 coding sequences involving the cysGHDNJI genes for sulfur acquisition which is missing in $\alpha 522$ as in most other meningococcal genomes.

\section{Both strains display similar phenotypes in ex vivo fitness and in vitro cell culture assays indicative of phenotypic buffering}

Despite the genetic differences described above, both strains were phenotypically similar with respect to resistance against human serum, adhesion to and invasion of nasopharyngeal cell lines, respectively, as well as in ex vivo growth (Table 1). Surprisingly, although meningococci are part of the human oral microbiome both strains were not able to grow in human saliva. Since strain MC58 was able to grow in meningococcal minimal medium (MMM), the observed growth inhibitory effect of human saliva was probably not due to nutrient limitation but more likely caused by the presence of growth inhibiting substances known to be present in human saliva like antimicrobial peptides [44]. Of note, in their ecological niche, the human nasopharynx, meningococci are attached to host cells in the form of microcolonies and are unlikely to grow in a planktonic state as in the ex vivo situation $[45,46]$. The fact that bacteria in biofilms are less susceptible to antimicrobial agents and host immune responses thereby becoming persistent colonizers [47] might explain the unexpected ex vivo growth phenotype in saliva. Furthermore, both strains grew equally well in human blood and CSF and thus under disease mimicking conditions despite their about 7-fold difference in the disease/carriage ratio (Table 1). These data indicate that the ability to survive in human blood is obviously necessary but per se not sufficient to cause IMD.
We therefore focused on compensatory mechanisms which might buffer the genotypic differences described above under ex vivo conditions and considered the transcriptome as an intermediate phenotype $[25,26]$. We hypothesized that both strains differ in the way they accomplish growth under disease mimicking conditions by differential transcriptional activation of metabolic and stress response pathways. For convenience, comparisons of the MC58 transcriptomes between saliva, whole blood and CSF, respectively, will be called cross-condition comparisons and discussed only briefly in the main text and in more detail in the Additional file 1. Likewise, comparisons of the transcriptomes of strain MC58 and $\alpha 522$ in saliva, whole blood and CSF, respectively, will be called crossstrain comparisons (Additional file 1: Figure S1). Genes differently expressed between two conditions or between both strains in a given condition will be called differently expressed genes, and genes differently regulated between both strains between two conditions will shortly be called differently regulated genes. Throughout the following analyses, we further discern directional and non-directional classes of gene sets. The non-directional class of significantly differently expressed genes contains genes where the information about direction of differential expression is omitted, so that significant gene sets can be interpreted as affected by differential expression in general. The directional class aims to identify gene sets that are significantly affected by regulation in a distinct direction, i. e. condition or strain. If a gene set contains significantly expressed genes in both directions, they will cancel out and the directional FDR-value will not be significant. In turn, if a gene set is not significantly enriched for differently expressed genes in general it might nonetheless comprise mainly genes with a significant expression bias in one direction. It consequently will have a non-significant nondirectional FDR-value but a significant directional FDRvalue.

\section{Condition-dependent expression changes affect $24 \%$ of the MC58 transcriptome}

Of the 1987 genes assayed in the cross-condition comparisons in strain MC58, 429 genes were differently expressed between saliva and blood and 151 between blood and CSF, respectively (Fig. 1a, c and Additional file 1: Figure S2A). Gene set enrichment analysis (GSA) showed that genes differently expressed between saliva and blood were significantly enriched for genes coding for nucleotide transport and metabolism (COG F) (Table 2), whereas genes differently expressed between blood and CSF were just slightly enriched for genes involved in posttranslational modification, protein turnover and chaperones (COG O, OR $=2.7, \mathrm{FDR}>0.10$ ) (Fig. 2a). GSA further showed significant differences also in the directionality of gene expression changes (Fig. 2b). 

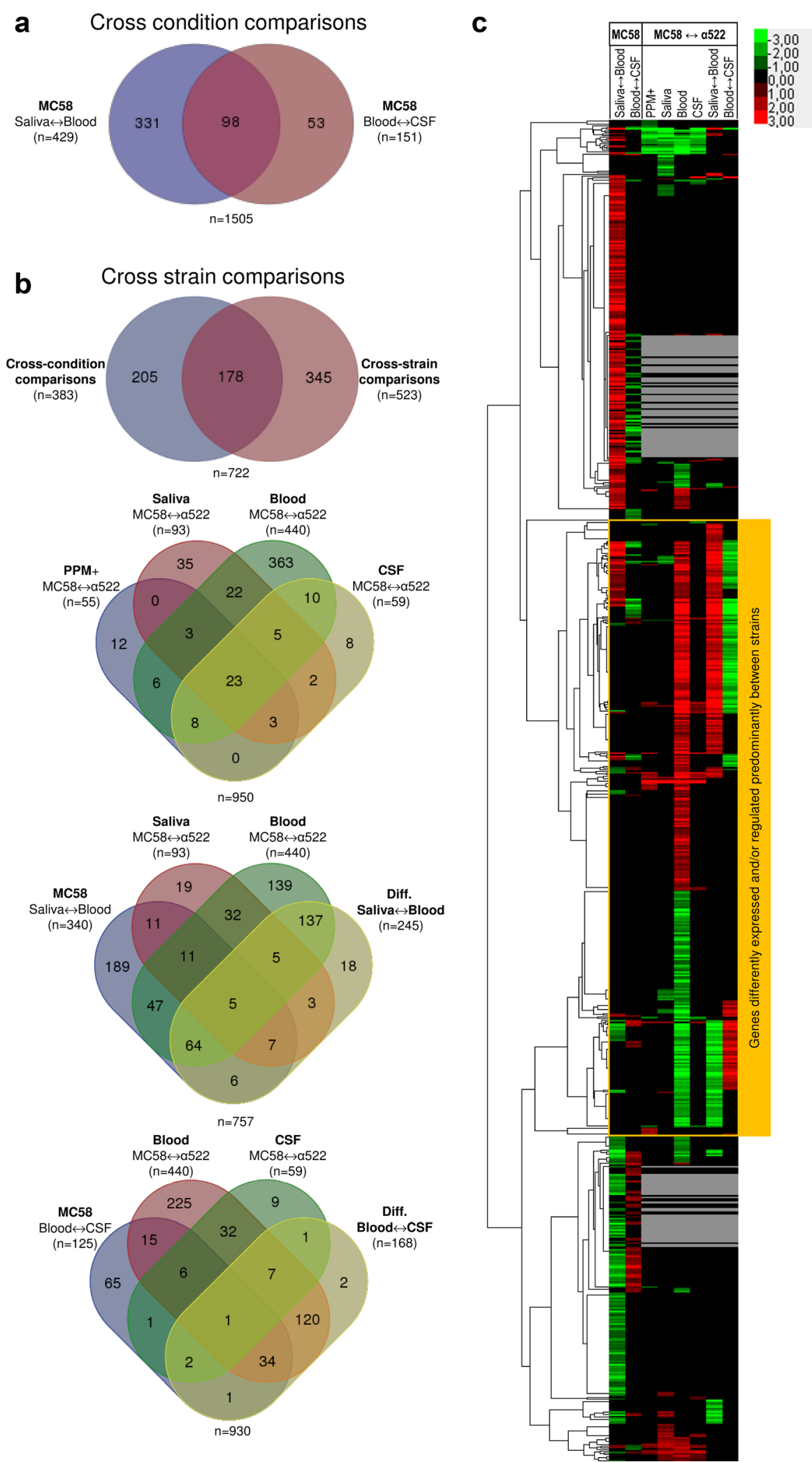

Fig. 1 (See legend on next page.) 
(See figure on previous page.)

Fig. 1 Genes significantly differently expressed and/or regulated in cross-condition and/or cross-strain comparisons. a Venn diagram comparing sets of genes in strain MC58 differently expressed between conditions as indicated. The total number of genes compared was 1987. $\mathbf{b}$ Venn diagrams comparing sets of genes differently expressed between strains as indicated with each diagram. The total number of genes compared in each panel was 1450. c Heatmap depicting cross-condition and cross-strain gene expression differences and hierarchical clustering of significantly differently expressed genes. Average linkage clustering based on the Spearman rank correlation of all 828 genes significantly differently expressed and/or regulated in at least one cross-condition and/or cross-strain comparison (FDR $<0.05$ ). Grey lines correspond to genes that were absent in the a522 genome sequence and therefore excluded from the cross-strain comparisons

The 173 genes that showed higher expression levels in saliva compared to blood were enriched for genes involved in energy metabolism and conversion (COG C), posttranslational modification, protein turnover and chaperones (COG O) and cell envelope and outer membrane biogenesis (COG M). However, genes that were more highly expressed in blood than in saliva and CSF, respectively, were significantly enriched predominantly for genes coding for proteins without any COG functional annotation so far, suggesting that our knowledge about the mechanisms employed by meningococci to survive in human blood are still quite limited.
Both strains differ in the expression of over 500 genes in a condition and strain dependent manner

Based on the genome comparisons we further selected a sub-set of 1450 single-copy orthologous genes for crossstrain gene expression comparisons. Of these, 523 were expressed and/or regulated at significantly different levels between both strains (Additional file 1: Figure S2A and Fig. 1b, c). Notably, proteins differently expressed in at least one ex vivo condition were not significantly more variable between both strains as indicated by their BSRPs than proteins that were not $\left(\mathrm{BSRP}_{\text {constant }}=0.993\right.$ vs. BSRP $_{\text {diff. expressed }}=0.995$, Wilcoxon test, $p>0.05$ ),

Table 2 Significantly enriched COG functional categories in cross-condition and cross-strain comparisons






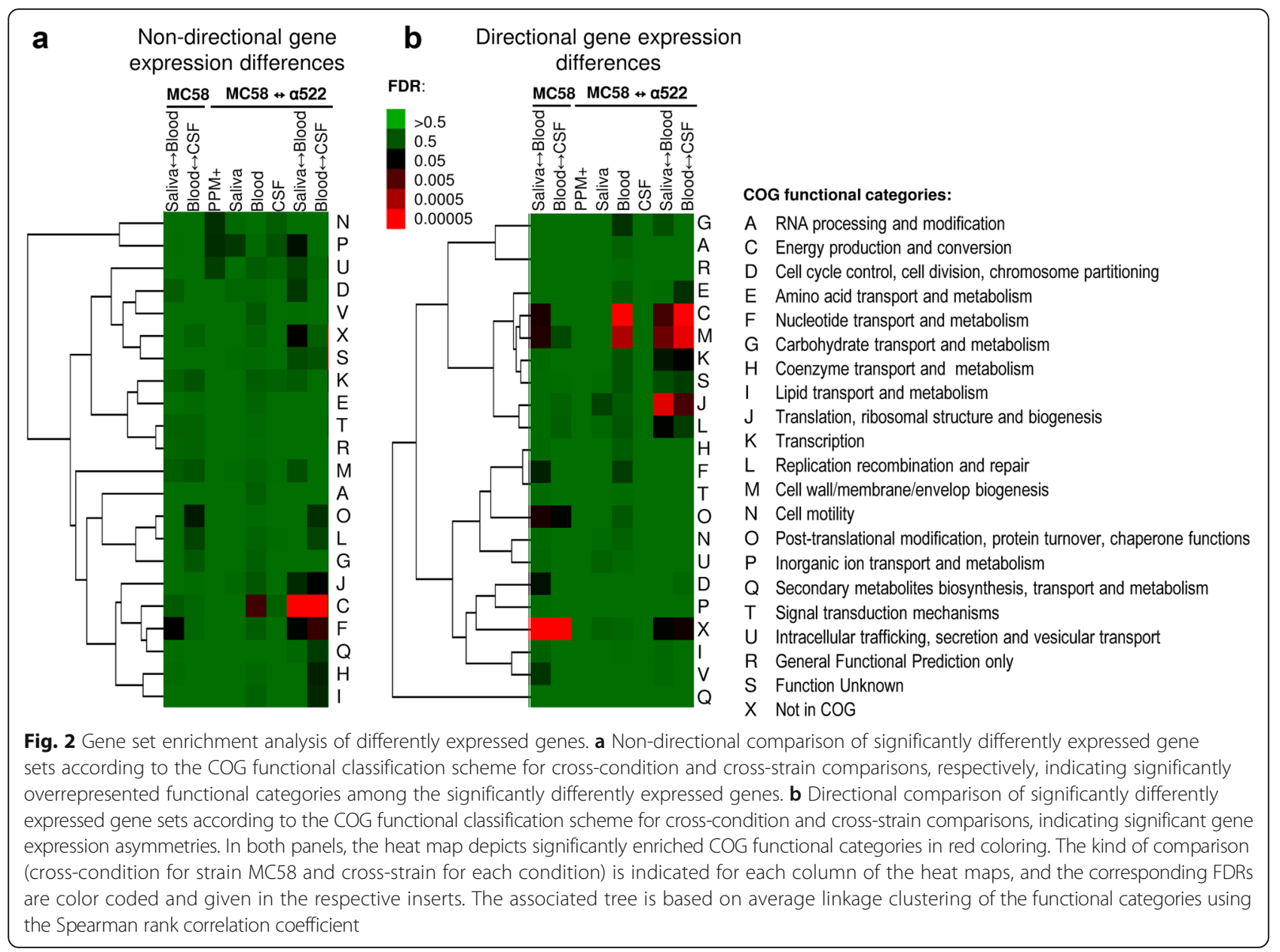

confirming that there was no significant sequence bias in the expression data.

Of all the 728 genes that showed cross-condition and/ or cross-strain expression differences 345 were differently expressed only in cross-strain and 205 only in cross-condition comparisons, respectively, and the overlap between cross-condition and cross-strain expression comparisons was thus surprisingly small (Fig. 1b). The total number of significantly differently expressed genes between both strains was small in rich medium (PPM+) $(n=55)$ and CSF $(n=59)$ and not significantly greater than the number expected by chance (FDR $<0.05$, binomial test, $p>0.10$ ), and there were only 8 and 12 genes that showed significant expression level differences between both strains exclusively in CSF and PPM+, respectively. The number of differently expressed genes was significantly higher for saliva $(n=93)$ and blood $(n=440)$ (binomial test, $p<0.01)$ than expected by chance $(F D R>0.05)$, although both strains were not able to grow in saliva. This further suggests that gene expression differences were not due to growth rate differences but were specific responses of both strains to these two ex vivo conditions. In line with this hypothesis, the transcriptomes differed significantly among both strains in response to the ex vivo condition tested (Pearson's $\chi^{2}$ test, $p<10^{-15}$ ). Of note, the pattern of transcriptionally activated genes upon transition from saliva to blood was opposite to the pattern of transcriptionally activated genes upon transition from blood to CSF (Figs. 1b and 2b), indicating that transcriptional changes are likely in response to components present in human blood but neither in saliva nor CSF. Since these two ex vivo compounds were both free of any phagocytic cells, differences in transcriptional responses in both strains might be triggered by blood phagocytes.

\section{Cross-strain gene expression differences in saliva comprise numerous stress response genes}

A total of 93 genes were differently expressed between both strains in saliva, with a slight yet not significant enrichment of genes involved in anorganic ion transport and metabolism ( $n=10$, COG P) (Fig. 2a). Functionally, around one third coded each for poorly characterized proteins $(n=27$, COGs $\mathrm{R}, \mathrm{S}$ and $\mathrm{X})$, proteins involved in cellular processes $(n=34)$ or proteins involved in 
metabolism or information storage and processing. Among the 55 genes highly expressed in strain $\alpha 522$ were, amongst others, seven for anorganic ion transport and metabolism proteins (COG $\mathrm{P}$ ) including a putative multidrug resistance protein (NMB0393), the lactoferrinbinding protein $\mathrm{A}(\mathrm{LbpA})$ and the putative ammonium transporter $\mathrm{AmtB}$, as well as six genes involved in cell envelope biogenesis (COG M) including genes for the two sialic acid capsule biosynthesis proteins SynX/SiaA/CssA and $\mathrm{SiaB} / \mathrm{CssB}$. Genes involved in translation and ribosomal biogenesis (COG J) comprised the single largest group $(n=10)$ among the genes that were in turn highly expressed in strain MC58 in saliva, next to genes in amino acid transport and metabolism $(n=4$, COG E) and cell envelope biogenesis $(n=4$, COG M). Since both strains were not able to grow in human saliva these gene expression differences likely reflect differences in the stress response between both strains when exposed to this hostile environment.

\section{Both strains differed in the expression of virulence- associated genes involved in the pathogenesis of IMD}

Numerous genes involved in the interaction of meningococci with its human host have so far been studied in order to understand the genetic and mechanistic basis of meningococcal virulence, i.e. host damage, and were consequently of special interest. Accordingly, of the 102 virulence-associated genes used for cross-strain comparisons (compiled from ref. $[21,38-40]$ ) (Additional file 2: S1), 48 were differently expressed and/or regulated among both strains under at least one of the ex vivo conditions tested which is significantly more than in the cross-condition comparisons for strain MC58 (2-sample test for equality of proportions, $p<0.01$ ) (Table 3 ). In addition, genes differently expressed and/or regulated between both strains in at least one cross-strain comparison were significantly enriched for virulence-associated genes $(\mathrm{OR}=1.55, p<0.05)$, and the expression profiles were significantly different between virulence-associated and not virulence-associated genes (Pearson's $\chi^{2}$ test, $\left.p<10^{-15}\right)$. Of the 38 virulence-associated genes that were differently expressed between both strains in blood, 16 were highly expressed in $\alpha 522$ and comprised genes involved in cell envelope biogenesis and in particular genes for capsule and LOS biosynthesis. LOS was shown to be the dominant molecule in meningococci inducing organ inflammation in human patients [48], and differences in LOS biosynthesis might therefore have an immediate impact on the extent of host damage caused by both strains. In turn, genes involved in type IV pilus biosynthesis iron homeostasis, the stress response genes as well as genes encoding adhesins such as Opc or the hemagglutinin/hemolysin-related protein TpsA3 or NspA [49] were all highly expressed in MC58. Besides Opc, we could at best detect only very small expression level differences for other recently introduced vaccine antigens that were conserved in both strains (NMB1030 and NMB2091).

Likewise, of the 37 genes that have been described so far as being involved in neutrophil interactions in Neisseria and which were part of the gene expression comparisons [38], 15 were differently expressed between both strains in blood (Additional file 2: S1). Genes differently expressed between both strains were therefore significantly enriched for neutrophil response genes $(\mathrm{OR}=2.9, \quad p<0.01)$. These included a number of virulence-associated genes like capsule synthesis genes or genes coding for efflux pump components (Table 3), as well as genes not so far associated with meningococcal virulence like the DNA damage repair genes $u v r A$ and $u v r B$. This finding indicates that neutrophils might have an important role in shaping the meningococcal transcriptional response to human blood.

Of note, aniA (also annotated as panI) encoding nitrite reductase and norB coding for NO reductase [50] showed the largest blood-specific expression differences between both strains (8- to 32 -fold) and were among the highest expressed genes in MC58 as was also confirmed by qRT-PCR (Additional file 1: Figure S3). The gene products AniA and NorB constitute a pathway that enables the organism to grow under conditions of low oxygen in the presence of nitrite. Amongst others, meningococcal derived $\mathrm{NO}$ was recently shown to play an essential role in the pathophysiology of septicemic meningococcal infection in humans by inhibiting platelet aggregation [51] and modifying the release of cytokines and chemokines by human macrophages [52].

Therefore, a number of virulence-associated genes with an also experimentally established role in the pathogenesis of IMD like aniA or LOS biosynthesis genes were differently expressed in both strains particularly in human blood.

\section{Transcriptomic differences between both strains associated with the transition from saliva to blood are enriched for metabolic, information processing and cell envelope biogenesis genes}

Overall, the number of differently expressed genes between both strains was highest in blood $(n=440)$, and also the number of genes differently regulated between both strains between two conditions was highest between saliva and blood ( $n=245)$ (Fig. 1). Both gene sets were functionally enriched for genes required for energy production and conversion (COG C) (Fig. 2a, Table 2). These data thus clearly demonstrate differences in the 
environment-dependent gene-expression regulation between both strains. The 196 genes highly expressed in strain $\alpha 522$ in human blood were significantly enriched for genes involved in cell wall/membrane biogenesis (COG M) (Fig. 2b, Table 2), including LOS and peptidoglycan biosynthesis genes like murB, murD, murE and $d d l$. In contrast, the 244 genes highly expressed in strain MC58 were significantly enriched for metabolic genes (COG C) including genes for oxidative phosphorylation (nqrBDF) and nitrogen respiration such as aniA and nor $B$ described above.

With respect to differences in the direction of gene expression regulation in both strains, genes required for energy production and conversion (COG C) were also strongly upregulated in strain MC58 between saliva and blood, whereas genes for cell envelope biogenesis (COG $\mathrm{M})$ and translation (COG J) were in turn strongly upregulated in strain $\alpha 522$.

Based on differences in the directionality of gene expression levels and regulation (Fig. 2b), the functional categories COG E, $\mathrm{C}$ and $\mathrm{M}$ form a cluster of coregulated genes which is part of a larger cluster including also the functional categories COG J, COG $\mathrm{K}$ and COG L. This finding suggests a regulatory link between metabolism, the biosynthesis of the cell envelope, and genes for the gene expression machinery which is differently activated in both strains particularly in human blood.

\section{Integrative network analysis of differently expressed genes identifies subnetworks of co-regulated genes}

In order to identify differentially expressed functional subnetworks, we combined the transcriptomic with protein-protein interaction (PPI) network data of strain MC58 as deposited in the STRING database and used an algorithm which optimally identifies responsive subnetworks [53, 54]. This integrative network analysis revealed a densly connected subnetwork comprising mainly genes that are highly expressed in strain MC58 in blood (30/35 genes, 2-sample test for equality of proportions, $p<10^{-5}$ ) involved particularly in energy and carbohydrate metabolism (Fig. 3a). This subnetwork comprised genes of the tricarboxylic acid (TCA) cycle ( $a c e F, s d h C, s u c A, s u c C$, sucD), for the metabolism of pyruvate $(a c c B)$, glycine $(g c v H, g c v T)$, leucine (leuA, leuB $)$ and fatty acids $(a c c B, a c p-2, f a b D, f a b H)$. The second subnetwork contained significantly more genes highly expressed in strain $\alpha 522\left(62 / 128\right.$ genes, $\left.p<10^{-4}\right)$ coding for a significantly different array of cellular functions (Pearson's $X^{2}$ test, $p<10^{-6}$ ). It comprised genes involved in the biosynthesis of the capsule $(\operatorname{siaA} / \operatorname{syn} X$, siaB), peptidoglycan (murB, murD, murE), and LOS $(k d t A, \operatorname{lp} x B)$, respectively, as well as genes for trafficking, secretion and vesicular transport (dprA, ffh) or information storage and processing including in particular translation and ribosomal biogenesis genes (rpmE, map). A few genes in this second subnetwork were highly expressed in MC58 yet and included genes for glycolysis (eno, galM, gapA-2, glk, pgm), the genes for the $\mathrm{Na}^{+}$-translocating NADH-quinone reductase subunit $\mathrm{B}, \mathrm{D}$ and $\mathrm{F}$ ( $n q r B, n q r D, n q r F)$ along with virulence-associated genes mentioned above like $d s b A-1$, pilG, pilT-2, sodC (Table 3). Transcriptomic differences in both strains in blood were thus organized in two subnetworks consisting mainly of genes that were either highly expressed in $\alpha 522$ or in MC58 and that coded for different biological functions.

Along with these cross-strain differences in the directionality of gene expression levels also cross-strain differences in the directionality of gene regulation between saliva and blood were organized in two functionally differing subnetworks (Pearson's $\chi^{2}$ test, $p<10^{-6}$ ) (Fig. 3b). The first subnetwork consisted almost exclusively of genes found to be upregulated in MC58 in blood compared to saliva $(47 / 59$ genes, $p<0.001)$, and over $70 \%$ of the genes in this subnetwork code for metabolic functions compared to only $24 \%$ in the other subnetwork $(\mathrm{OR}=7.25, p<0.001)$. It comprised genes for TCA cycle enzymes (icd, lpdA1, sdhB, sucA, sucC, sucD), for 2oxocarboxylic acid metabolism (asd, leuB), oxidative phosphorylation (petA, fixO, nuoA), fatty acid metabolism ( $a c c B, a c p-2, f a b G, f a b H)$, for thioredoxin-fold proteins (kat, NMB0946, NMB1366, sodC) required for oxidative stress response as well as the oxidoreductase genes $n q r B, n q r D, n q r F$ and $a n i A$, the latter playing a major role in the pathogenesis of IMD as described above. The second subnetwork consisted of genes that were strongly upregulated in strain $\alpha 522$ in blood compared to saliva $\left(15 / 25\right.$ genes, $\left.p<10^{-7}\right)$ and included predominantly genes involved in information storage and processing and in particular for the translation machinery (hisS, prmA, map, NMB0347, NMB0348).

In line with the GSA results, integrative network analysis thus indicated that in contrast to strain $\alpha 522$ strain MC58 allocates transcriptional resources predominantly in the expression of metabolic genes in human blood.

\section{Elementary mode analysis of blood transcriptomic data indicate compensatory flux differences between both strains particularly in energy, glutamine and cysteine metabolism}

In order to assess the possible impact of the transcriptomic differences on metabolism in blood in more detail, we reconstructed a condensed metabolic network based on the Nmb_iTM560 model for strain MC58 [55] comprising 123 enzymes (complexes) and 129 metabolites. The 54 elementary metabolic modes and pathways as identified by elementary mode analysis [56] are given in the Additional file 3: S2. 


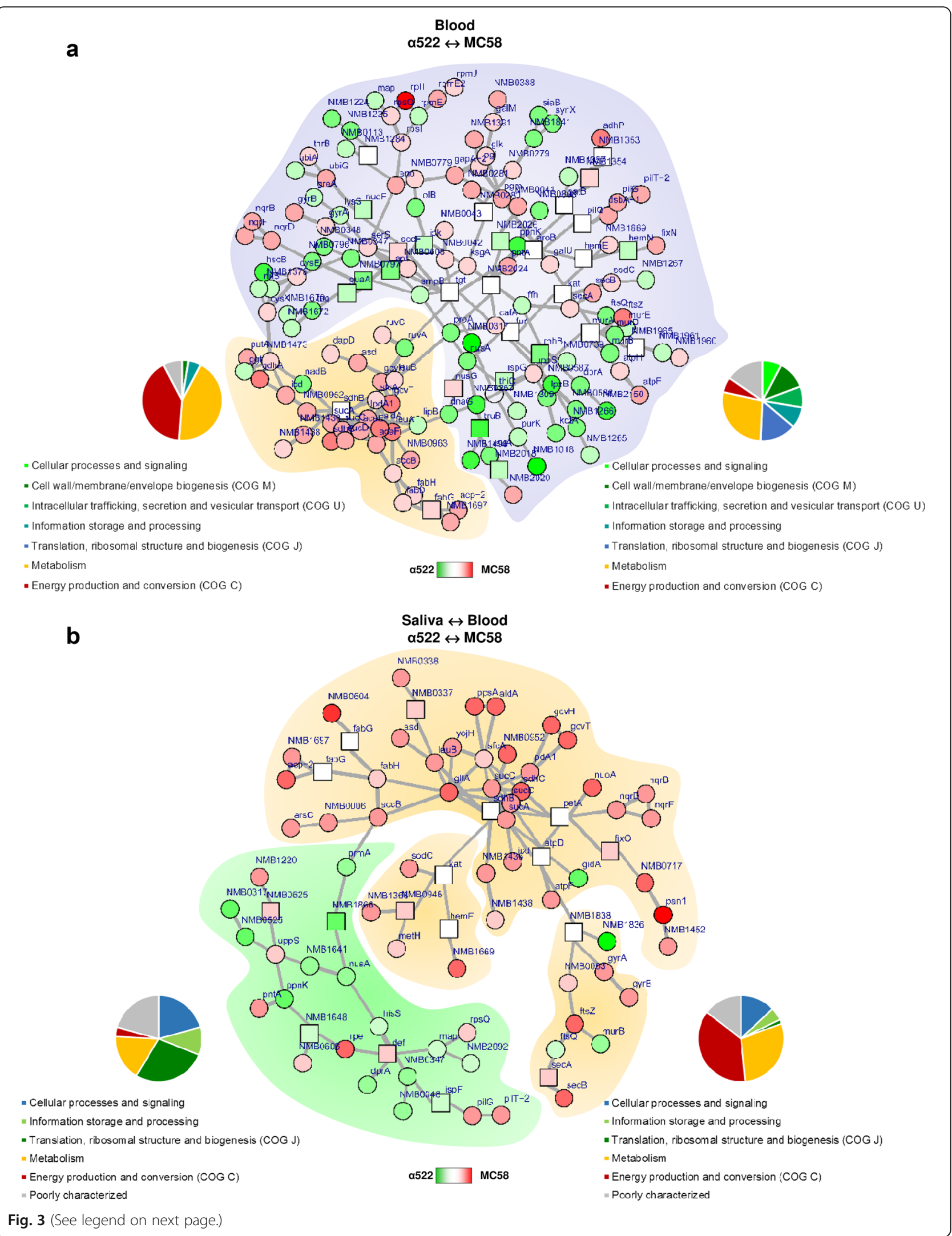




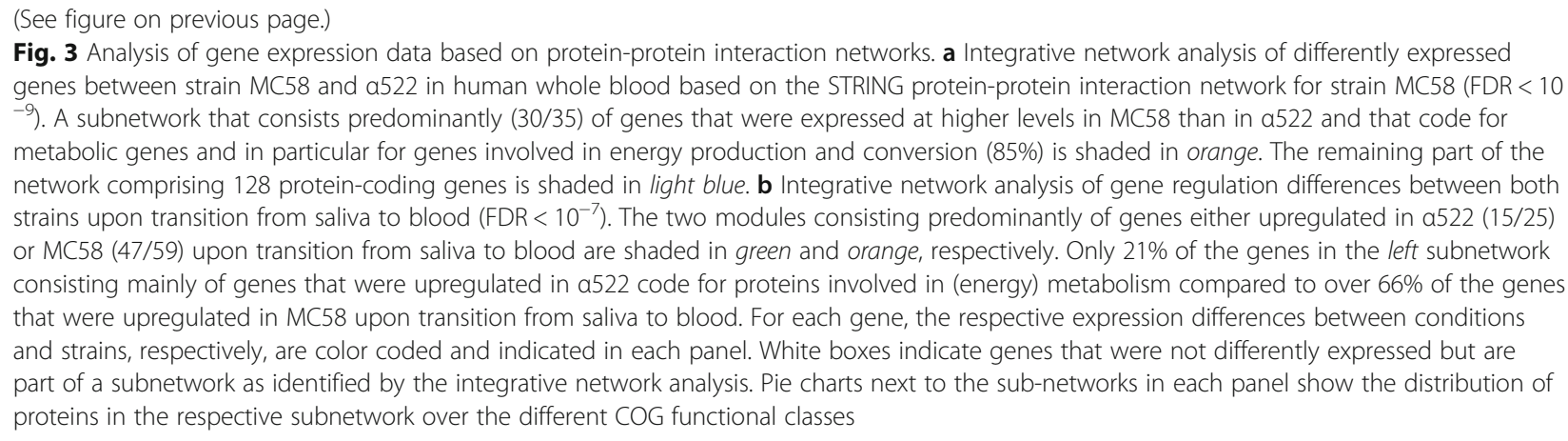

Computation of metabolic fluxes [57] based on the observed growth rates of both strains in human blood (Table 1), the corresponding gene expression data (Additional file 2: S1) and the average composition of human blood as taken from [58] showed that the flux activities in MC58 were $25-50 \%$ higher than in $\alpha 522$ with major differences in the metabolism of some amino acids (flux ratios higher than 6 or lower than 0.72) (Fig. 4a). Of note, one flux mode (EM 05) displayed an opposite direction between MC58 and $\alpha 522$, indicating that $\alpha 522$ uses a large amount of external glutamine (Gln) from human blood to produce gutamate (Glu).

For more detailed information about differences in important biochemical pathways, we converted the flux activities into enzyme and enzyme complex activities, respectively. The major differences are given in Table 4 and Fig. 4b. Only very few fluxes were slightly stronger in $\alpha 522$ such as R049, R050 and R132 which are all involved in sulfur metabolism. On the other hand, there were numerous reactions that were even more than tenfold stronger in MC58 than in $\alpha 522$ such as the acetate synthesis reactions R117, R118 and R155 suggesting that MC58 compared to $\alpha 522$ may accumulate acetate as intermediate metabolite in this environment. In meningococci, such metabolic stimulation has been shown to result from the consumption of lactate which in the presence of glucose is used as a source of additional energy [59]. Of note, lactate is a by-product of neutrophil glycolysis and enhances bacterial consumption of molecular oxygen, which depletes the substrate for neutrophil NADPH oxidase and thus blunts its oxidative burst [38]. Since both strains have almost identical growth rates in human blood (Table 1) MC58 probably requires this additional metabolic energy for other, not growth related processes such as, e.g., defense against the neutrophil oxidative burst. Other reactions that were particularly stronger in MC58 included R001, R002 and R015 leading from phosphoenolpyruvate (PEP) to $\alpha$ ketoglutarate (AKG) as well as some reactions involved in amino acid metabolism like R052 and R053 resulting in the synthesis of serine (Ser) from Glu and glycine (Gly), respectively, or R056, R062 and R063 resulting in the synthesis of leucine (Leu), phenylalanine (Phe) and tyrosine (Tyr) from Glu, respectively. Since the reactions R052, R056, R062 and R063 are all transamination reactions resulting in the consumption of Glu and concomitant synthesis of AKG, these findings further suggest that MC58 and $\alpha 522$ might differ in their intracellular levels of Glu and AKG in human blood. Finally, reactions R030 and R031 have opposite directions in both strains in human blood, which indicates that $\alpha 522$ relies mostly on Gln to produce Glu with some Glu being further converted into AKG, whereas MC58 is capable to produce enough Glu from the TCA cycle and convert it further to Gln. Likewise, also reaction R047 which is the production of cysteine (Cys) from serine (Ser) has an opposite direction in both strains in human blood, and $\alpha 522$ consequently seems to rely on external Cys to produce Ser whereas MC58 is capable of producing Cys from Ser.

\section{Strain a522 differs from strain MC58 in Gln and Cys auxotrophy in vitro}

In order to experimentally validate the transcriptomic results with respect to possible differences in Gln and Cys metabolism, we assessed the growth of both strains in MMM supplemented with different amino acids as well as PPM+ (Fig. 5a). Whereas both strains were equally able to grow in PPM+ and MMM supplemented with all 20 proteinogenic amino acids at milimolar concentrations, strain $\alpha 522$ was not able to grow in MMM without amino acids. In addition to glucose or lactose as carbon source (data not shown) it requires Cys and Gln for growth (Additional file 1: Figure S4). Contrary to $\alpha 522$, the growth of MC58 was slightly suppressed by these two amino acids. The ability of MC58 but not a522 to grow in the absence of Cys and Gln indicates strain specific differences in the respective metabolic pathways, and the requirement of some meningococcal strains for Cys and its growth inhibiting effect on others has already been reported [60]. In parallel with these 
Ampattu et al. BMC Genomics (2017) 18:282

Page 12 of 36

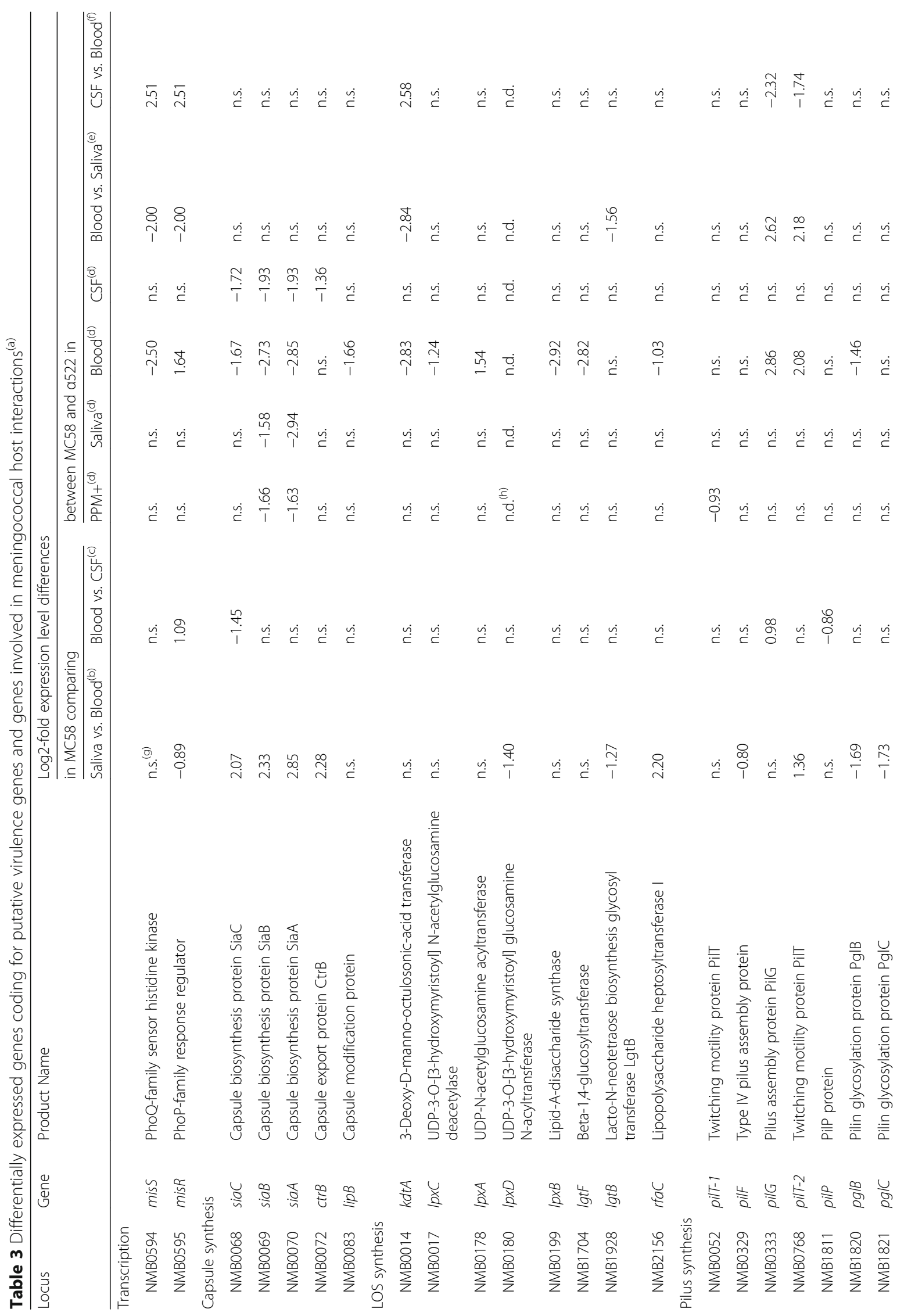


Ampattu et al. BMC Genomics (2017) 18:282

Page 13 of 36

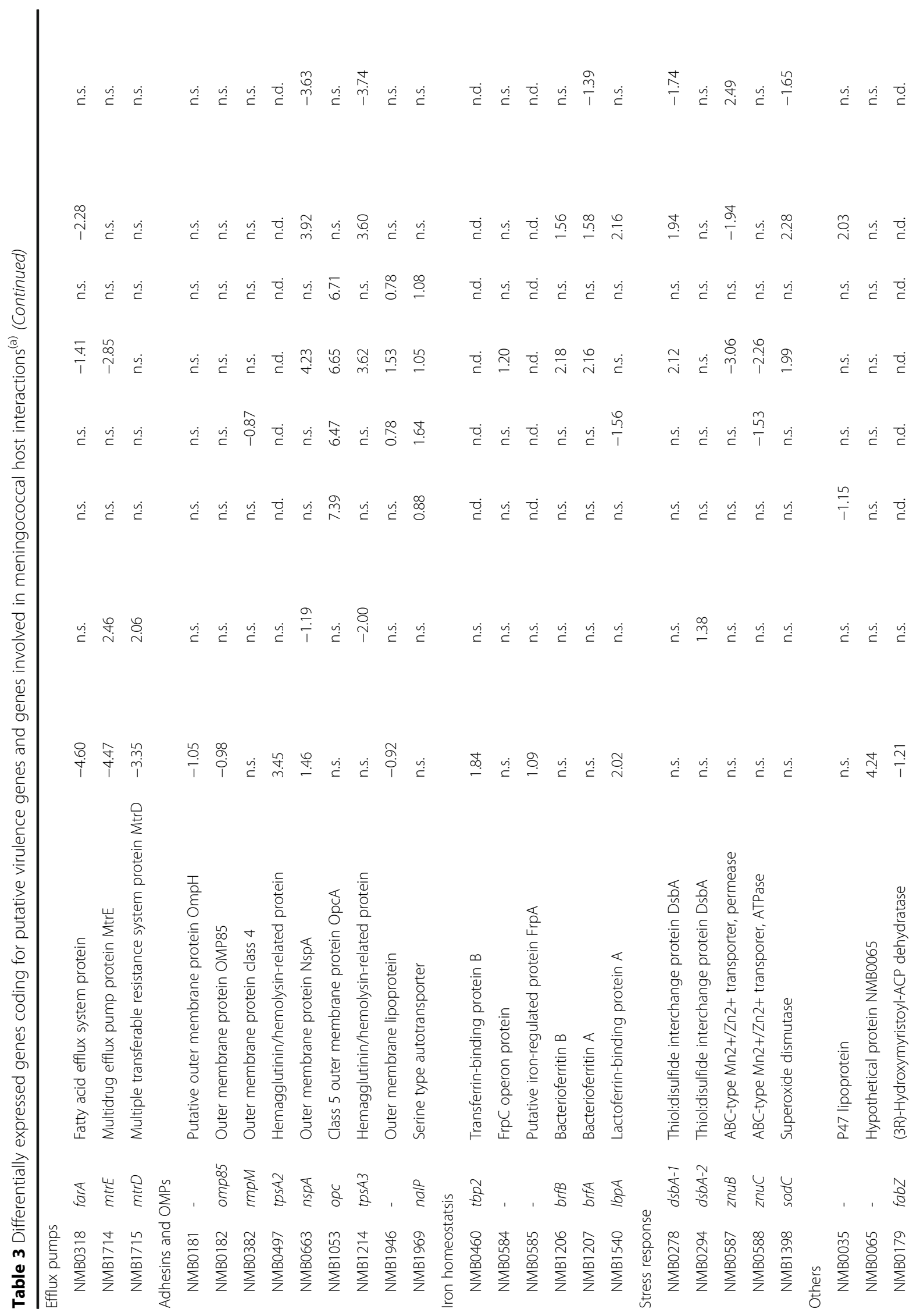




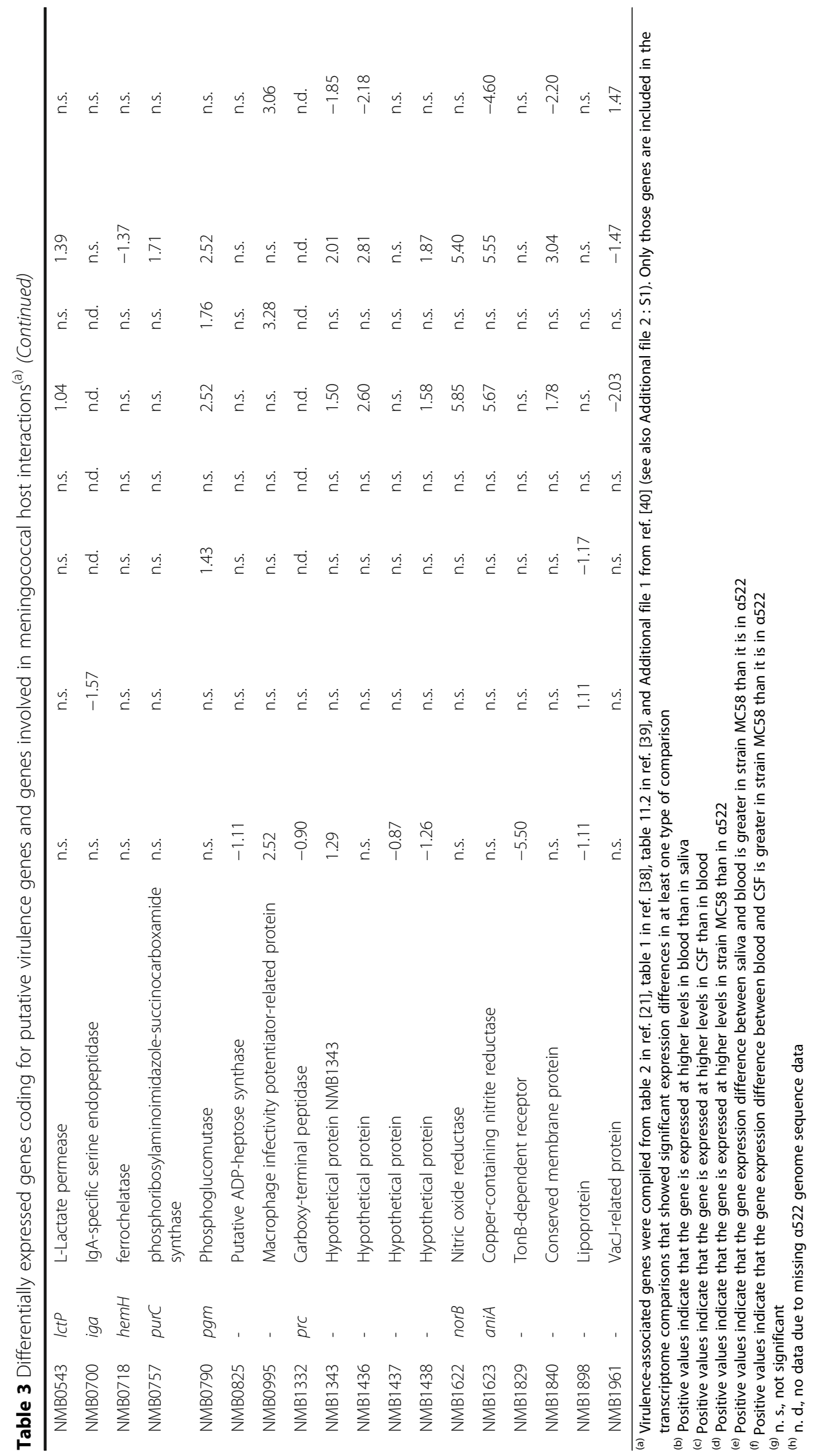


a

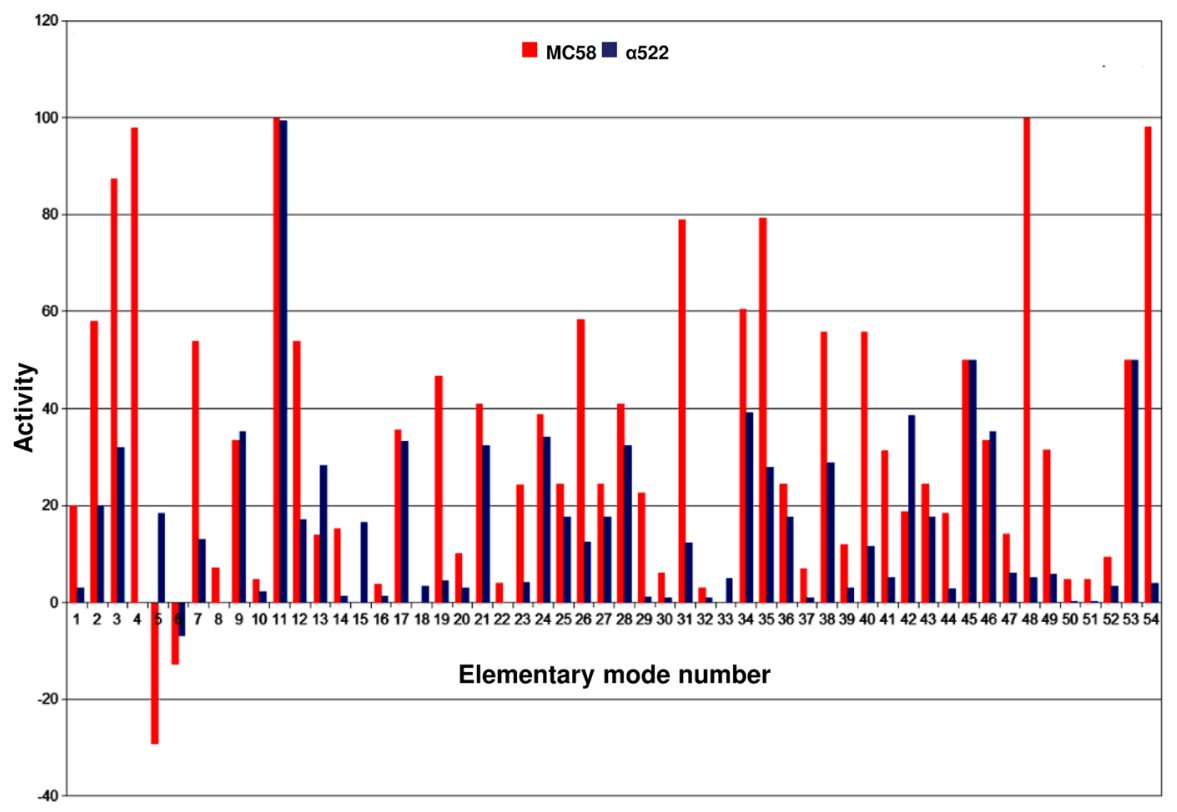

b
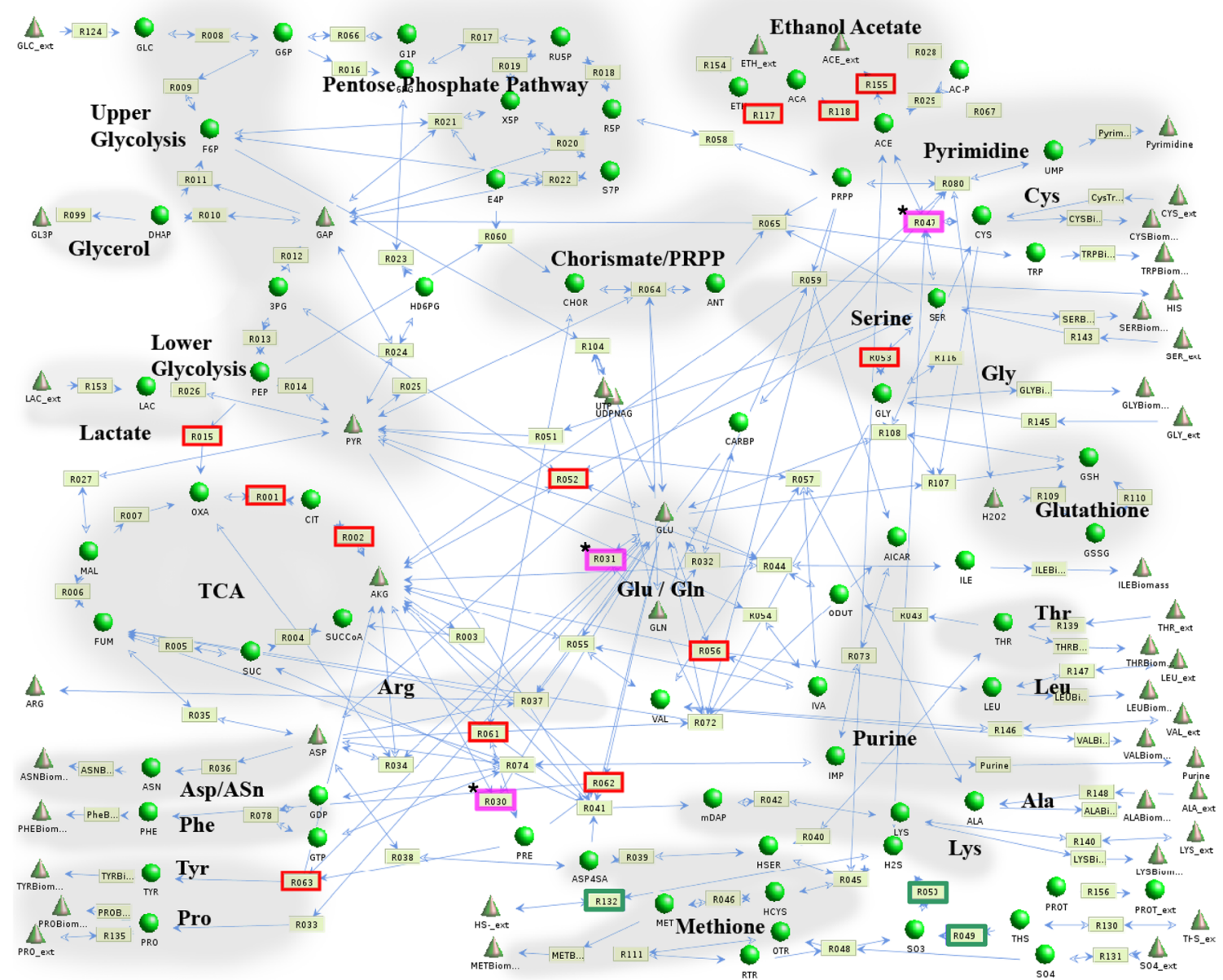

Fig. 4 (See legend on next page.) 
(See figure on previous page.)

Fig. 4 Analysis of gene expression data based on a metabolic model for strain MC58. a Comparison of elementary mode activities in MC58 and a522. The histogram depicts differences in the elementary mode activities (ordinate) for each of the elementary metabolic modes (abscissa) as defined in the Additional file 3: S2 for strain MC58 (red) and a522 (b/ue) based on gene expression data in human blood. b Inferred differences in metabolic fluxes between strain MC58 and strain a522 in blood based on a metabolic model for strain MC58. Internal metabolites which are considered to have balanced concentrations are given by dark green spheres, external metabolites which are allowed to accumulate or to be consumed by green cones, and reactions together with their corresponding numbers as light green boxes. The reactions for all reaction numbers are given in the Additional file 3: S2. Arrows connect reaction with metabolites. Red coloring indicates higher fluxes in MC58 compared to strain a522, whereas blue colouring indicates that the flux is slightly enhanced in a522. Asterisks along with pink colouring indicate that the reaction has an opposite direction in both strains

phenotypic differences, genome comparisons revealed also striking differences in Cys and Gln biosynthesis genes that might contribute to the phenotypic finding, although the repertoire of enzymes required for the biosynthesis of amino acids is otherwise highly conserved in both genomes. In addition to the duplication of cysGHDNJI genes in MC58 (Additional file 1: Figure S2A), these include large sequence differences in the phosphoadenosine phosphosulfate reductase $\mathrm{CysH}$ and the glutamate-ammonia-ligase adenylyltransferase GlnE which are among the least conserved genes involved in the biosynthesis of amino acids (Additional file 1: Figure $\mathrm{S} 2 \mathrm{C}$ ). CysH is required for the reduction of sulfate into hydrogen sulfide and thus for sulfur acquisition in N. meningitidis [61], and GlnE is a key regulatory enzyme in nitrogen assimilation in E. coli [62]. Furthermore, the intergenic region between purL and $\operatorname{gln} B$ differs in both strains due to the insertion of coding sequence in strain $\alpha 522$ upstream of $g \ln B$ resulting in entirely different $g \ln B$ promoter regions (Additional file 1: Figure S2D). Along with $\mathrm{GlnE} G \ln B$ is involved in the regulation of nitrogen assimilation in $E$. coli via affecting the activity of GlnA, an enzyme that lies at the heart of the nitrogen assimilation network. GlnA is involved in the complex regulation of the interconversion of Glu to Gln in response to the intracellular concentration of ammonium, Glu, the Gln/AKG ratio, the redox (NADPH) and the free energy state of the cell [62]. Sequence variation at these loci is therefore likely to have pleiotropic effects, and a detailed experimental analysis of the biochemical

Table 4 Inferred reaction activity differences between MC58 and a522 in human blood based on gene cross-strain expression differences

\begin{tabular}{|c|c|c|c|}
\hline Reaction & Chemical Equation & Enzyme(s) & $\operatorname{Ratio}^{(\mathrm{a})}$ \\
\hline R030 & $\mathrm{AKG}+\mathrm{NADPH}+\mathrm{NH}_{3}=\mathrm{GLU}+\mathrm{NADP}$ & Glutamate dehydrogenase & -14.85 \\
\hline R031 & $\mathrm{ATP}+\mathrm{GLU}+\mathrm{NH}_{3}=\mathrm{ADP}+\mathrm{GLN}$ & Glutamine synthetase & -3.03 \\
\hline R047 & $\mathrm{ACCOA}+\mathrm{H} 2 \mathrm{~S}+\mathrm{SER}=\mathrm{ACE}+\mathrm{CYS}+\mathrm{COA}$ & Serine acetyltransferase + cysteine synthase & -2.32 \\
\hline R001 & $\mathrm{AcCOA}+\mathrm{OXA}=\mathrm{CIT}+\mathrm{COA}$ & Citrate-synthase & 13.86 \\
\hline R002 & $\mathrm{NADP}+\mathrm{CIT}=\mathrm{CO}_{2}+\mathrm{NADPH}+\mathrm{AKG}$ & Aconitase & 13.86 \\
\hline R015 & $\mathrm{CO}_{2}+\mathrm{PEP}=\mathrm{OXA}$ & Phosphoenolpyruvate carboxylase & 11.90 \\
\hline R052 & $3 P G+G L U+N A D=A K G+N A D H+S E R$ & $\begin{array}{l}\text { Serine synthesis: } 3 P G \text { dehydrogenase }+ \text { pserine aminotransferase }+ \\
\text { pserine phosphatase (SerA }+ \text { SerB }+ \text { SerC) }\end{array}$ & 7.63 \\
\hline R053 & $\mathrm{SER}=\mathrm{GLY}$ & Serine hydroxymethyltransferase & 7.45 \\
\hline R056 & $\begin{array}{l}\mathrm{AcCOA}+\mathrm{GLU}+\mathrm{IVA}+\mathrm{NAD}=\mathrm{AKG}+\mathrm{CO}_{2}+ \\
\mathrm{COA}+\mathrm{LEU}+\mathrm{NADH}\end{array}$ & $\begin{array}{l}\text { Leucine synthesis: isopropylmatate synthase + isopropylmalate } \\
\text { dehydratase + isopropylmalate dehydrogenase + aminotransferase } \\
(\text { LeuA + LeuB + LeuC + LeuD) }\end{array}$ & 6.78 \\
\hline R061 & $\mathrm{CHOR}=\mathrm{PRE}$ & Chorismate mutase & 12.58 \\
\hline R062 & $\mathrm{GLU}+\mathrm{PRE}=\mathrm{AKG}+\mathrm{CO}_{2}+\mathrm{PHE}$ & Aminotransferase + phenyalanine synthesis & 12.58 \\
\hline R063 & $\mathrm{GLU}+\mathrm{NAD}+\mathrm{PRE}=\mathrm{AKG}+\mathrm{CO}_{2}+\mathrm{NADH}+\mathrm{TYR}$ & Aminotransferase + tyrosine synthesis & 12.58 \\
\hline R117 & $A C A+N A D H=E T H+N A D$ & Alcohol dehydrogenase & 14.74 \\
\hline R118 & $A C E+N A D H=A C A+N A D$ & Aldehyde dehydrogenase & 14.74 \\
\hline R155 & $A C E=A C E \_$ext + H_ext & Acetate transporter & 11.50 \\
\hline R049 & $\mathrm{O}_{2}+\mathrm{THS}=2 \mathrm{SO}_{3}$ & Thiosulfate reductase & 0.61 \\
\hline R050 & $3 \mathrm{NADPH}+\mathrm{SO}_{3}=\mathrm{H}_{2} \mathrm{~S}+3 \mathrm{NADP}$ & Sulfite reductase & 0.71 \\
\hline R132 & $\mathrm{H}_{2} \mathrm{~S}=\mathrm{HS}^{-} \_$ext $+\mathrm{H} \_$ext & Sulfur transporter & 0.45 \\
\hline
\end{tabular}

(a) Ratio of the reaction activity in MC58 divided by the reaction activity in a522. A ratio larger than one indicates that the reaction has a higher activity in MC58, and a negative ratio that the reaction occurs in opposite directions both strains 

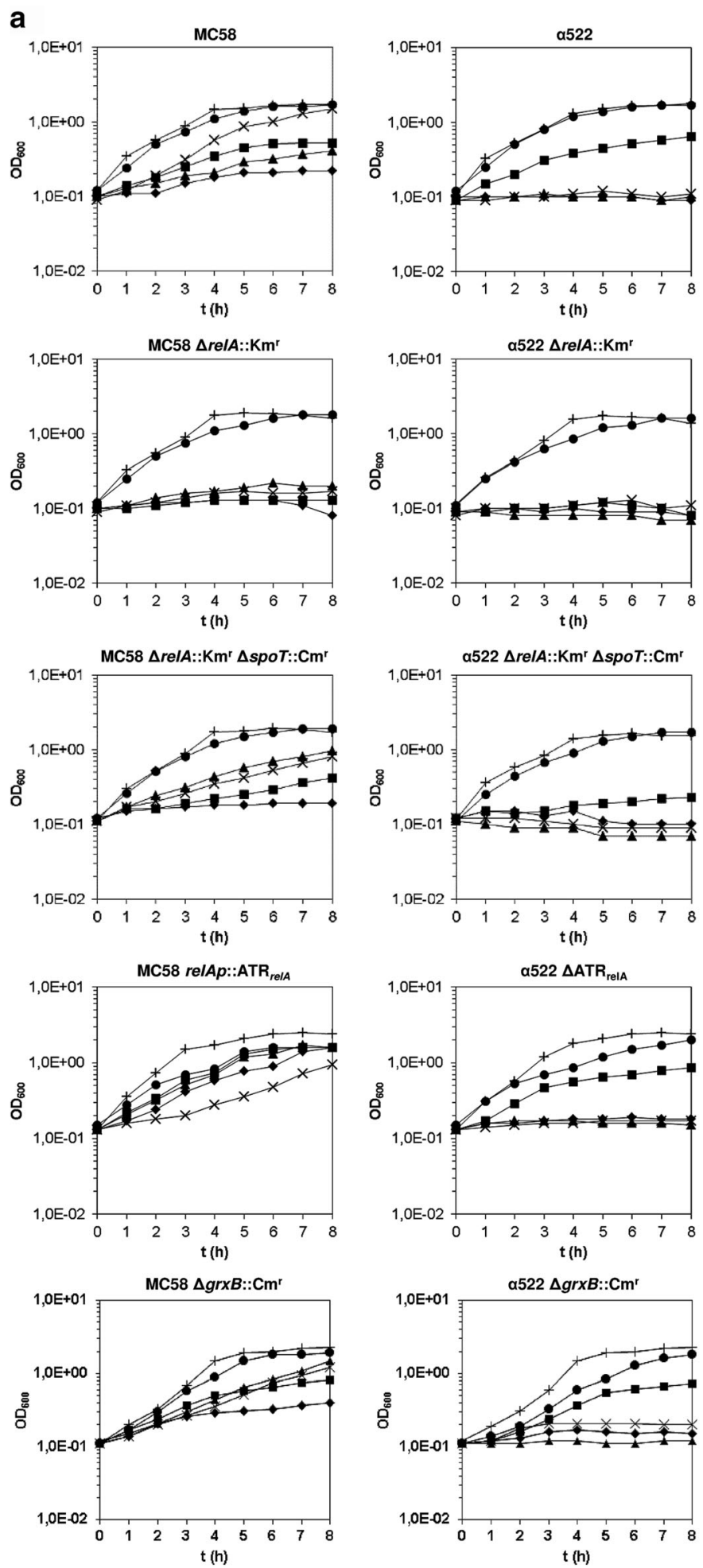

$\leftarrow \mathrm{MMM} \multimap \mathrm{MMM}+$ Cys $\multimap-\mathrm{MMM}+\mathrm{Gln}$

- $\mathrm{MMM}+$ Cys $+\mathrm{Gln} \longrightarrow \mathrm{MMM}+20 \mathrm{AA} \rightarrow \mathrm{PPM}+$
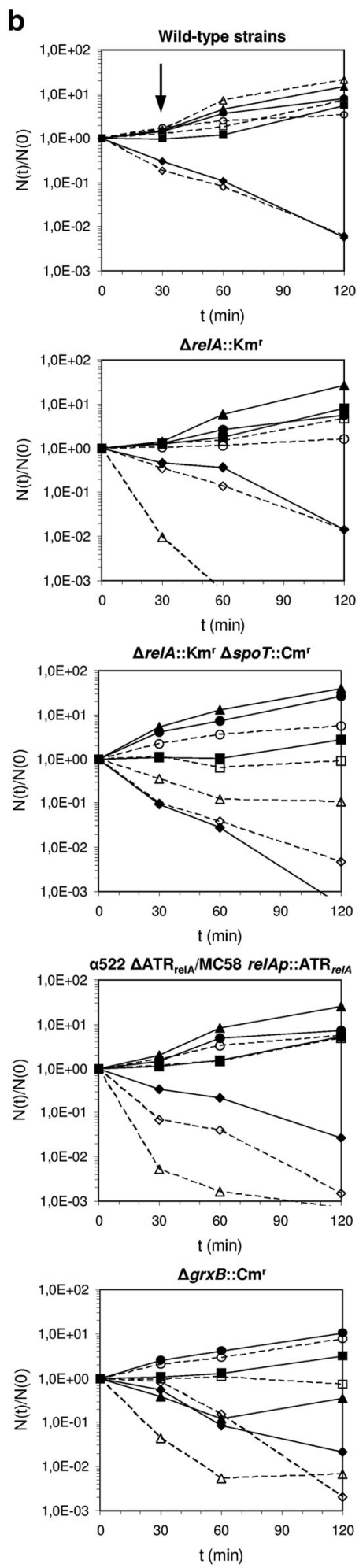

PPM+ Saliva Blood CSF MC58 $\rightarrow-\longrightarrow \rightarrow-\bullet$

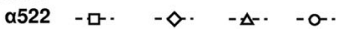

Fig. 5 (See legend on next page.) 
(See figure on previous page.)

Fig. 5 Growth phenotypes of N. meningitidis MC58 and a522 wild-type and mutant strains. a In vitro growth phenotypes. Growth as quantified by the optical density $\left(\mathrm{OD}_{600 \mathrm{~nm}}\right)$ is given on the ordinate and the time in hours on the abscissa. $\mathbf{b}$ Ex vivo growth phenotypes. The number of colony forming units for each time point $(N(t))$ relative to the initial number $(N(0))$ is given on the ordinate and the time in minutes on the abscissa. For each strain and condition the respective growth curves are coded as indicated in the insert in each panel, and the genotypes of the respective strains compared are shown along with the corresponding growth curves. In each experiment rich medium (PPM+) was used as growth control. The arrow at the top of panel $\mathbf{b}$ indicates the time when total RNA was extracted for microarray analysis

consequences of these genetic differences is subject to ongoing work.

\section{Expression changes in numerous regulatory genes are likely compensatory}

The large transcriptome differences observed particularly in blood could be caused by differences in regulatory elements acting either in cis or in trans, or be compensatory to ensure cellular homeostasis. Among the 1757 orthologous proteins those involved in gene expression regulation (COG $\mathrm{K}$ and $\mathrm{T}$ ) were no more different between both strains than proteins involved in other functions $\left(\mathrm{BSRP}_{\mathrm{COGK} / \mathrm{T}}=0.9944\right.$ vs. $\mathrm{BSRP}_{\text {other }}=$ 0.9936, Wilcoxon test, $\mathrm{p}>0.05)$. Also the $200 \mathrm{bp}$ upstream regions were not less conserved than the downstream orthologous genes $\left(\mathrm{BSRN}_{5}{ }^{\prime}-\mathrm{UTR}=0.9823 \mathrm{vs}\right.$. BSRN $_{\mathrm{CDS}}=0.9671$, Wilcoxon test, $\left.\mathrm{p}>0.05\right)$. Of the 1450 single-copy orthologous genes used for transcriptomic comparisons 30 differed in the presence of putative mobile genetic elements within their 200 bp upstream regions (Additional file 2: S1). These comprised various so called minimal mobile elements $[63,64]$ as well Correia repeats and Correia repeat enclosed elements which have previously been shown to affect gene expression in a polar manner [65-67]. However, this class of genes was not enriched for genes differently expressed in at least one ex vivo condition. Although genetic differences in gene regulatory elements might contribute to the transcriptomic differences these data do not provide evidence yet that they are the sole reason of the large crossstrain expression differences observed particularly in human blood. They might rather orchestrate different compensatory gene expression adaptations in both strains in response to differences in the interaction of both strains with human blood components.

\section{Both strains activate different sets of regulatory genes in response to human blood}

Of the 41 genes with significant expression differences in cross-condition or cross-strain comparisons involved in signal transduction or transcription (COG K or T), 18 showed significant expression level differences between both strains in blood (Table 5). The eight regulatory genes that were highly expressed in MC58 specifically in blood included in particular cstA annotated as carbon starvation protein A, NMB0398 coding for an ArsR family transcriptional regulator, $\mathrm{rel} A$ encoding the guanosine 3'-(tri)diphosphate 5-'diphosphate ((p)ppGpp) synthetase of the stringent response pathway, as well as misR (NMB0595) coding for a PhoP-family response regulator of a two component signal transduction system. Of note, 64 genes of the 440 genes differently expressed in blood belong to the MisR regulon [33], and MisR was shown to be involved in the oxidative stress response in meningococci [34], required for colonization of host cells [68] and meningococcal survival in mice [69]. In addition, 22 differently expressed genes which are part of the Fur regulon [70] were almost all highly expressed in MC58. Since Fur senses cellular iron concentrations and since iron in general acts as a corepressor, these data indicate that strain MC58 might experience more pronounced iron starvation in blood compared to strain $\alpha 522$. Likewise, another 45 genes are known to be regulated by FNR [32], the master regulator involved in the adaptation to oxygen-limited conditions, of which the majority (29) were also highly expressed in MC58.

In turn, the ten regulatory genes highly expressed in $\alpha 522$ included NMB0282 encoding a exoribonuclease and rpoE (NMB2144) which codes for the alternative sigma factor $\mathrm{E}\left(\sigma^{\mathrm{E}}\right)$ and in $N$. gonorrhoeae is activated in response to oxidative stress [71]. Since phagocytic cells are a major source of reactive oxygen species and were present only in the blood assay, these data further suggests that $\sigma^{\mathrm{E}}$ might be involved in meningococcal interaction with human phagocytes. In line with previous findings that the expression of aniA and $\operatorname{nor} B$ are under the negative control of $\sigma^{\mathrm{E}}[72]$, both strains also showed significantly different expression levels of aniA and norB especially in blood as mentioned above (Additional file 1: Figure S3). Along with the finding that nitric oxide (NO) generated by AniA inhibits platelet aggregation [51] this observation provides a direct link between the oxidative stress response and the pathophysiology of IMD. These data indicate that the complex gene expression differences between MC58 and $\alpha 522$ specifically in blood are caused by the activation of different sets of regulatory genes including MisR, Fur, FNR, RelA and $\sigma^{\mathrm{E}}$. In contrast to the expression of rpoE [72] and misR [33,34] which in both cases was found to be auto regulated, Fur and FNR did not differ in their expression between both strains, 
Ampattu et al. BMC Genomics (2017) 18:282

Page 19 of 36

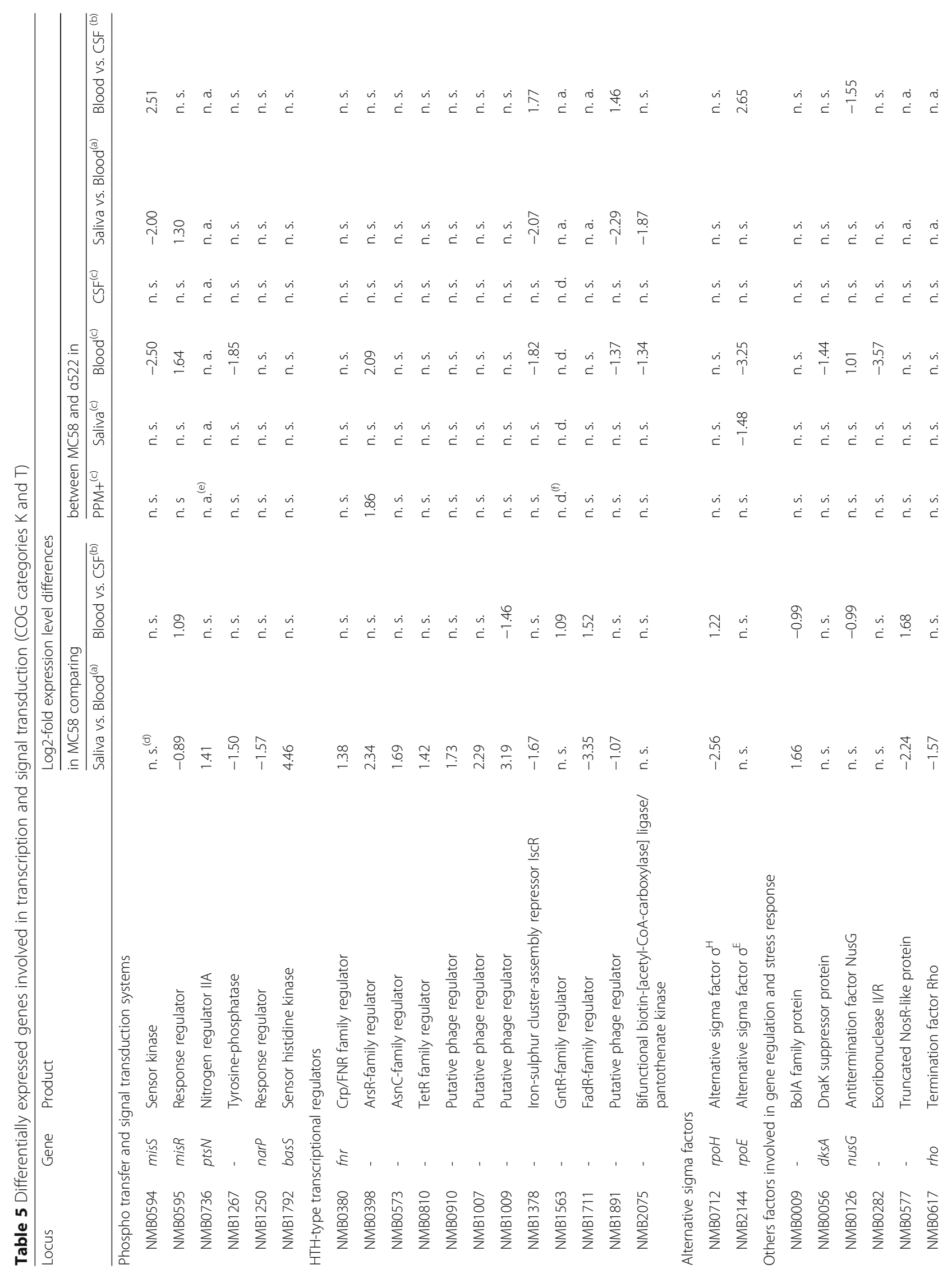




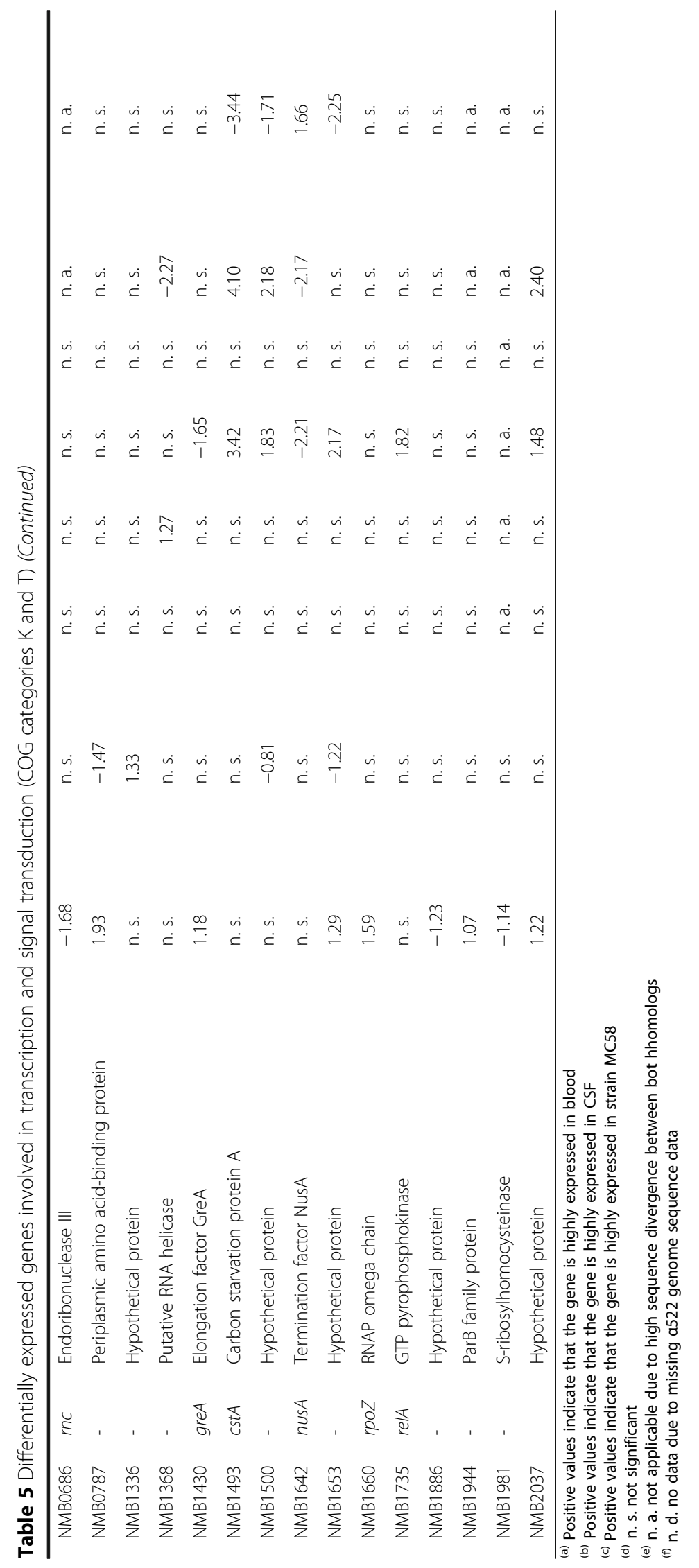


suggesting strain-dependent differences in the posttranscriptional activation of these regulators especially in blood.

\section{Differences in promoter regions demonstrate an important role for the stringent response and $\mathrm{Hfq}$ mediated differences in gene expression regulation among both strains in blood}

Although sequence analyses of the $200 \mathrm{bp}$ upstream regions of the 524 genes that were differently expressed between both strains in cross-strain comparisons failed to identify any consistent sequence differences or overrepresented bona fide TF binding sites for any of the cross-strain comparisons, the analysis of GC content variation yet revealed a 6 bp region immediately upstream of the predicted ribosome binding site (RBS) having a significantly lower GC content in genes that were expressed at higher levels in MC58 than in $\alpha 522$ in blood $\left(\mathrm{GC}_{\mathrm{MC} 58}=37 \%\right.$ vs. $\mathrm{GC}_{\alpha 522}=42 \%$, Wilcoxon test, $p<0.01$ ) (Fig. 6). At the mRNA level, such AU-rich elements next to the RBS are often targets for the Hfqmediated binding of small non-coding RNAs which thus post-transcriptionally regulate the degradation and/or translation efficiency of the corresponding mRNA [73]. In strain MC58, the RNA chaperone Hfq was already shown to be involved in the regulation of amino acid and energy metabolism, the oxidative stress response and required for survival in human blood [74]. The comparison of the differently expressed genes showed that of the 18 genes that are part of the Hfq regulon and that were included in this study, 9 were differently expressed in both strains, all higher in MC58.
Therefore, these data suggest that Hfq contributes to gene regulation differences between both strains in blood.

Furthermore, genes differently expressed between both strains in blood had also significant GC content differences in a $10 \mathrm{bp}$ region $40 \mathrm{bp}$ upstream of the predicted RBS $\left(\mathrm{GC}_{\mathrm{MC} 58}=44 \%\right.$ vs. $\mathrm{GC}_{\alpha 522}=48 \%$, Wilcoxon test, $p$ $<0.05$ ) (Fig. 6), and there was a negative correlation between expression differences in blood and the deviation from the average genomic GC content (Spearman's rank correlation $\rho=-0.12, p=0.01$ ). Since the average length of 5'-UTRs in Neisseria was shown to be between 40 and $50 \mathrm{bp}$ [75] this region corresponds to the transcriptional start site. The length of this region, its pattern of GC content variation and its location close to the presumed transcriptional start site are hallmark features of so called discriminator regions [76] which in $\gamma$ proteobacteria determine whether the adjacent gene is activated or repressed during the stringent response. Accordingly, of the 440 genes differently expressed between both strains in human blood, 117 have a discriminator GC content higher than the genome-wide average of $50 \%$ and were highly expressed in $\alpha 522$, and 131 genes with a discriminator $\mathrm{GC}$ content lower than the average were highly expressed in MC58 (OR $=1.69, p<$ 0.01 ). Together, these genes account for $56 \%$ of all genes differently expressed in blood. Since activated targets typically have an AT-rich discriminator whereas repressed targets have a GC-rich discriminator, these data along with the higher expression of relA in MC58 indicate that in blood the stringent response pathway is comparatively more activated in MC58 than in $\alpha 522$.
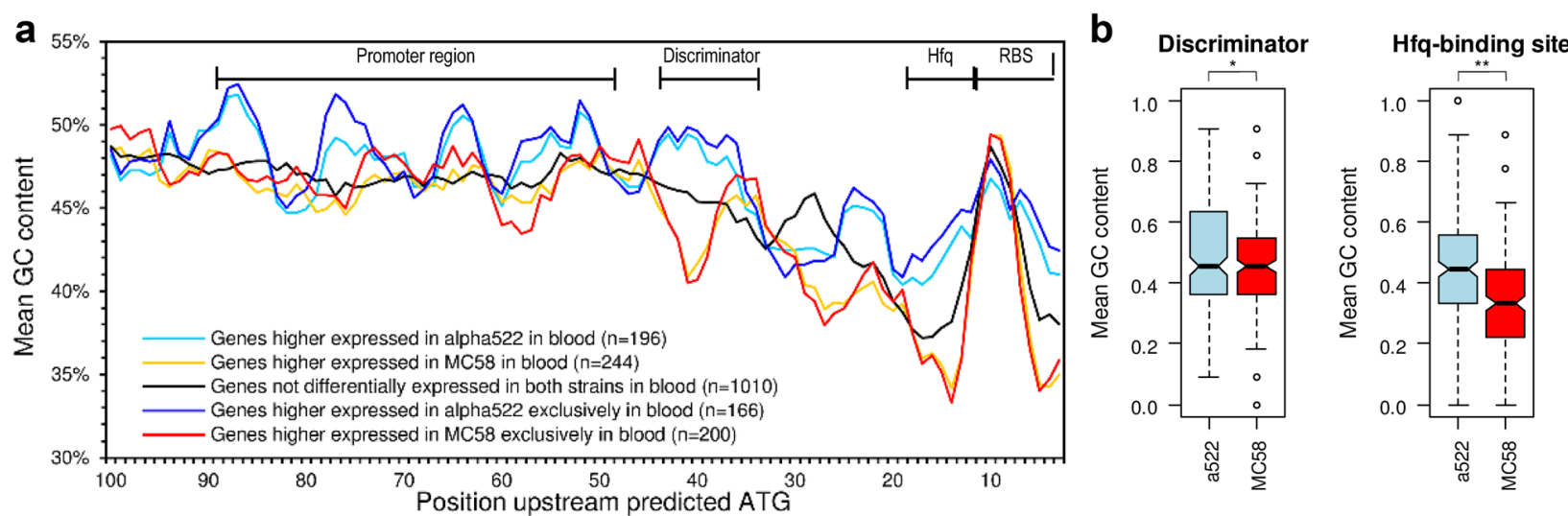

Fig. 6 GC content variation in potential promoter regions based on the MC58 genome sequence. a Scatter plot of the GC content variation averaged over a 5-bp sliding window within 100 bp upstream regions for genes highly expressed in MC58 (red and yellow lines) or a522 (light and dark blue lines) in human blood. The black line gives the GC content of the respective upstream regions for genes not differently expressed. Regulatory regions are indicated at the top of the panel based on the average length of $5^{\prime}$-untranslated regions in $\mathrm{N}$. gonorrhoeae [75]. The insert gives the number of genes in each gene set. $\mathbf{b}$ Box-and-whiskers plot depicting differences in the mean GC content of the putative discriminator (left) and Hfq-binding regions (right) between genes highly expressed in MC58 (red) or a522 (blue) in human blood as depicted in panel (a). The line within each box gives the median and the upper and lower margins the upper and the lower quartile, respectively. The whiskers denote the highest and the lowest values, respectively, and the open circles outliers. * $p<0.05, * *: p<0.01$ (Wilcoxon test) 
Genes highly expressed in MC58 and with a low GC discriminator region were predominantly involved in energy production and conversion (COG $\mathrm{C}, \mathrm{OR}=4.79$, $p<0.05)$ and comprised genes involved in carbohydrate (pykA, mapA, pgm, rpe, suhB) and energy metabolism ( $h p r A$, nиоA, nиоG, nuоL, nqrF, sdhC, lpdA1, pntA, leuB, fum $C$, fix $O$, ald $A$, etf $A$ ), in aerobic energy generation (sdhC, ccoN (NMB1725), ccoO (NMB1724)), the genes for cytochrome c4 (NMB1805) and c5 (NMB1677)) as well genes required for the oxidative/nitrosative stress responses (bfr $A B, g l t S, g s h A, \operatorname{grx}, \operatorname{sod} C)$ along with surface proteins like NspA, Lip and Laz. Genes highly expressed in $\alpha 522$ and having a high GC discriminator region were predominantly involved in cell envelope and outer membrane biosynthesis (COG M, OR $=11.7, p<$ $0.001)$ and included genes for LOS $(k d t A, \operatorname{lp} x B)$ and peptidoglycan biosynthesis ( fts $W$, murD, murE, $d d l$ ) as well as regulatory genes including rpoE.

\section{RelA and the stringent response pathway contribute to meningococcal ex vivo fitness in a condition and strain dependent manner}

Although the stringent response pathway was already shown to be crucial for virulence in a number of bacterial pathogens [76], nothing is known about its contribution to meningococcal ex vivo or in vitro fitness so far. Therefore, the observation that relA was differently expressed between both strains exclusively in blood along with the finding that genes differently expressed between both strains in blood had significant GC content differences in their putative discriminator regions prompted us to further assess the contribution of the stringent response and in particulate of relA to meningococcal fitness ex vivo.

The machinery of the stringent response pathway comprises several enzymes involved in the turnover of (p)ppGpp which is a signaling nucleotide that coordinates a variety of cellular activities in response to changes in nutritional abundance [76]. In E. coli, RelA is activated upon amino acid starvation and together with SpoT is able to catalyze pyrophosphoryl transfer from ATP to GTP or GDP to synthesize (p)ppGpp. Together with DnaK suppressor (DksA), (p)ppGpp directs transcription initiation at particular gene promoters through binding to the interface between the two RNA polymerase subunits $\beta^{\prime}$ and $\omega[77,78]$. In part, (p)ppGpp and DksA act by promoting the interaction of RNA polymerase with alternative $\sigma$-factors such as $\sigma^{\mathrm{E}}$ or $\sigma^{\mathrm{H}}$. When metabolic precursors are plentiful, SpoT instead degrades (p)ppGpp, and the vegetative $\sigma$-factor, $\sigma^{70}$, directs RNA polymerase to genes that are crucial for bacterial replication. Whereas $\beta$,' $\omega$, SpoT and DksA were identical in both strains they differed in the coding sequences and promoter region of RelA (Fig. 7a), and gene expression analyses via $\mathrm{qRT}-\mathrm{PCR}$ further confirmed particular large and blood-specific cross-strain expression differences for relA but not for spoT or $d k s A$ (Additional file 1: Figure S3).

To test whether these differences in the coding sequences of relA affected its catalytic activity we assessed ppGpp levels in wild-type, $\Delta$ relA:: $\mathrm{Km}^{\mathrm{r}}$ as well as $\Delta$ relA $:: \mathrm{Km}^{\mathrm{r}} \Delta$ spoT:: $\mathrm{Cm}^{\mathrm{r}}$ mutants in both strains during growth in PPM+ medium. As can be seen in Additional file 1: Figure S5A, both alleles were catalytically active and the catalytic activity was affected by the bacterial growth phase in a similar manner. Similar to the $\alpha 522$ wild-type strain, the MC58 $\Delta r e l A:: \mathrm{Km}^{\mathrm{r}}$ mutant could further not grow in minimal medium, and in both genetic backgrounds the addition of all 20 proteinogenic amino acids could compensate for the loss of functional RelA but not the addition of only Cys and/or Gln to minimal medium (Fig. 5a). In addition, similar to E. coli (p)ppGpp ${ }^{0}$ strains the growth defect in minimal medium was less severe in meningococcal $\Delta$ relA:: $\mathrm{Km}^{\mathrm{r}} \Delta s p o T:: \mathrm{Cm}^{\mathrm{r}}$ double mutants. In support of the notion that (too) high levels of (p)ppGpp might be toxic for the meningococcal cell we could not obtain viable isogenic spoT single deletion mutants, and a presumed spoT knock-out mutant had a compensatory frame-shift mutation prior the catalytic domain of relA resulting in reduced ppGpp levels (Additional file 1: Figure S5B and C).

With respect to ex vivo fitness the deletion of relA had no effect in MC58 on growth in saliva, blood or CSF whereas the $\alpha 522 \Delta \operatorname{relA}:: \mathrm{Km}^{\mathrm{r}}$ mutant was severely impaired exclusively in blood (Fig. 5b). The ex vivo fitness defect was less severe in a $\alpha 522 \Delta \operatorname{relA}:: \mathrm{Km}^{\mathrm{r}} \Delta s p o T:: \mathrm{Cm}^{\mathrm{r}}$ double mutant. Unfortunately, since all attempts to clone full-length relA and spoT, respectively, in $N$. meningitidis for cis/trans complementation assays failed, the possibility that the observed phenotypes are, at least in part, caused by polar effects cannot be ruled out entirely. However, as depicted in Additional file 1: Figure S6, there are rho-independent transcriptional terminators at the $3^{\prime}$ ends of the relA as well as the spoT gene which have not been altered in the respective mutants. Furthermore, since the phenotype of the $\mathrm{ATR}_{\text {relA }}$ mutants particularly in blood resembles the phenotype of the relA mutants in both strains, and since both are also different from the phenotype of the $\operatorname{gr} x B$ mutants, it seems rather unlikely that the relA phenotype is due to a polar effect on $\operatorname{grx} B$ expression (and vice versa) and not due to the decreased (p)ppGpp levels (Additional file 1: Figure S5).

Together, these data show that that the stringent response pathway is functional in both meningococcal strains despite their different relA alleles. The deletion of $r e l A$ is conditional lethal and it is differently expressed between both strains under virulence-mimicking conditions in human blood. The effect of relA on ex vivo 


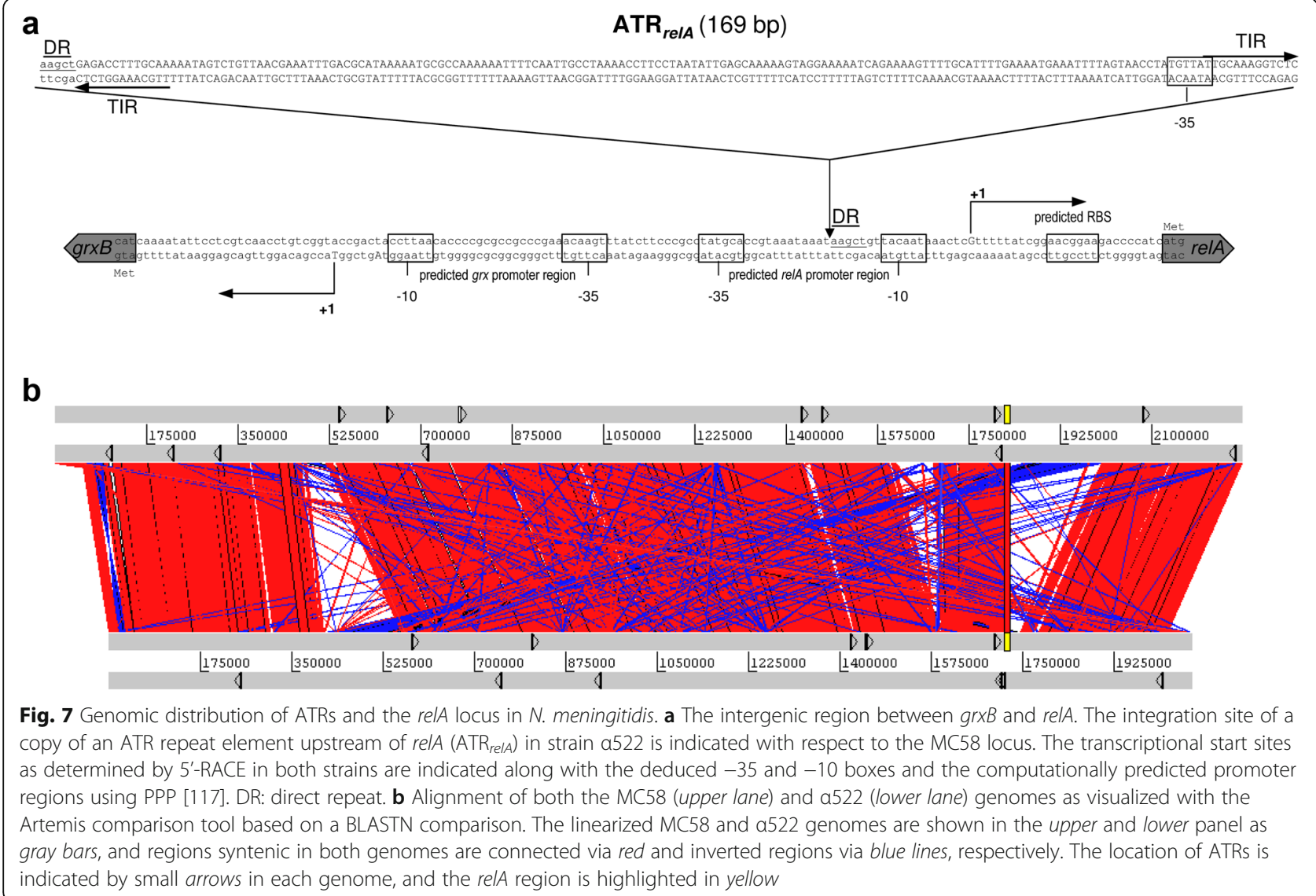

fitness is thus dependent on the environment and the genetic background.

\section{A non-coding mobile element affects meningococcal fitness in a strain- and condition-dependent manner} In addition to differences in the relA coding sequences, the intergenic region between relA and the upstream $\operatorname{gr} x B$ encoding the redox enzyme glutaredoxin differed substantially in both strains due to the integration of an AT-rich (ATR) repeat element in strain $\alpha 522$ (Fig. 7a). ATR repeat elements occur 12 and 13 times in the genomes of $\alpha 522$ and MC58, respectively, of which only 10 have the same position in both genomes (Fig. 7b). They have a conserved length of $181 \mathrm{bp}$ with ends forming a perfect 13-bp inverted repeat and belong to a class of non-autonomous DNA transposons also known as miniature inverted-repeat transposable-elements (MITEs) [79].

ATRs are almost exclusively located in intergenic regions in both genomes and are almost ten times more frequently found in intergenic regions flanked by convergently transcribed genes than expected by chance (Fisher's exact test, $\mathrm{OR}=9.64, p<0.001$ ). This indicates that the location in potential promoter regions might be under negative selection possibly due to adverse effects on the expression of neighboring genes. As experimentally determined by 5 -RACE, the -35 boxes of the relA promoter differ between both strains due to the insertion of $\mathrm{ATR}_{\text {relA }}$ in strain $\alpha 522$ between the -10 and -35 boxes (Fig. 7a). Furthermore, growth experiments demonstrated that the fitness of an $\mathrm{ATR}_{\text {relA }}$ knock-out strain was impaired only in $\alpha 522$ and only in human blood thus resembling the phenotype of the relA deletion mutant (Fig. 5b). In contrast to the deletion of $\mathrm{ATR}_{\text {relA }}$ or $r e l A$, the effect of deleting the neighboring $g r x B$ gene was condition- but not strain-dependent. These findings thus suggest that via affecting the expression of relA, differences in the binding of transcriptional regulators might contribute to the observed epistatic effects of $\mathrm{ATR}_{\text {relA }}$ on ex vivo fitness. The conditional essentiality of $\operatorname{grx} B$ for ex vivo fitness further supports the hypothesis that the oxidative stress response is required for blood survival especially in human blood. In support of a background- and condition-dependent effect of $\mathrm{ATR}_{\text {relA }}$ on meningococcal fitness, we could not observe any ex vivo fitness differences between the $\mathrm{ATR}_{\text {relA }}$ knock-in mutant strain MC58 relAp::ATR $\mathrm{AelA}_{\text {and }}$ and corresponding MC58 wild-type strain.

Surprisingly, the integration of $\mathrm{ATR}_{\text {relA }}$ into the relA promoter region abolished however the inhibitory effect 
of Cys and Gln on growth in MMM in strain MC58, whereas the deletion of $\mathrm{ATR}_{\text {relA }}$ had no effect on the in vitro growth of $\alpha 522$ (Fig. 5a). This suggests a link between Cys and Gln metabolism and the stringent response regulation in a yet to define epistatic manner. Although the role of MITEs in meningococcal infection biology has already been established [66] this is the first time that a biological function has been shown for the ATR class of MITEs in an infection process.

\section{Discussion}

It has recently been shown that transcriptional regulation in prokaryotes is more flexible than the genetic component of the organisms and that its complexity and structure plays an important role in phenotypic adaptation [11]. However, little is known so far about the significance of regulatory evolution that might underlie bacterial virulence. Accordingly, we used a hypothesisgenerating systems biological approach $[25,26]$ to analyse gene-expression differences between two meningococcal strains from a hyperinvasive and a carriage clonal complex, respectively, under infection-mimicking conditions (Additional file 1: Figure S1).

Despite the substantial genetic differences between both strains affecting surface antigens as well as metabolic genes likely affecting Cys and Gln biosynthesis (summarized in Fig. 8), both were surprisingly similar in a variety of in vitro virulence assays and in their growth behavior under infection mimicking conditions (Table 1 and Fig. 5). In particular, the finding that both strains have the same fitness in human blood and CSF despite the large differences in the disease/carriage ratios between CC ST-32 and CC ST-35 strains further indicates that the ability to grow under infection mimicking conditions might be necessary but not sufficient for explaining the invasive property of certain meningococcal lineages. Virulence, i.e. host damage, might rather be related to the way how meningococci accomplish growth in this environment. In line with this hypothesis, the large transcriptome differences observed particularly in human blood (Fig. 1) indicate that different transcriptional programs probably compensate for the differences in the genetic backgrounds of both strains in response to host components. This so called phenotypic buffering is a general property of complex gene-regulatory networks $[25,36]$.

Upon transition from commensal to invasive behavior meningococci have to adapt to the accompanying large environmental changes caused largely by differences in nutritional and innate immunity in these different compartments. These comprise, e.g., differences in the presence of professional phagocytes or the availability and concentration and of key nutrients such as amino acids or iron [80-82]. Accordingly, it has already been shown that the oxidative burst, which is one of the most prominent effector mechanisms in human neutrophils, is modulated by neisserial porins, and - although to a lesser extent - also Opc has been described to be involved in $N$. meningitidis - neutrophil interaction (reviewed in [83]). The observed differences in the repertoire and/or expression of, e.g., Opc, PorA and PorB, could lead to differences in the phagocytic uptake by neutrophils and/or the activation of the oxidative burst (Fig. 8). Phagocytosis and the activation of the neutrophil oxidative burst in turn exert nutritional and oxidative/nitrosative stresses on the bacterial cell $[38,82]$. The resulting damage to the bacterial cell triggers bacterial stress responses which in pathogenic bacteria have already been considered as virulence factors. In particular, lactate, a by-product of neutrophil glycolysis, was shown to enhance bacterial consumption of molecular oxygen in the presence of glucose, which depletes the substrate for neutrophil NADPH oxidase and thus blunts its oxidative burst [38, 59, 84]. Accordingly, our transcriptomic data analyses outlined above suggest a particularly strong metabolic activation in strain MC58 in blood (Figs. 1, 2, 3 and 4). Another important component in the oxidative/nitrosative stress responses in Neisseria is glutathione (GSH) [84]. It is synthesized from Cys, Gln/Glu and Gly which are either taken up from the environment or synthesized from precursors generated in the Entner-Doudoroff (ED) pathway and TCA cycle, respectively [85] (Fig. 8). Via the GSH cycle, the biosynthesis of Cys and Gln/Glu are thus linked to the oxidative/nitrosative stress response [86]. We therefore hypothesize that the observed sequence variations in metabolic genes such as $\mathrm{CysH}, \mathrm{G} \operatorname{lnE}$ or GlnB involved in Cys and Gln/Glu biosynthesis, respectively, lead to the activation of compensatory transcriptional programs to allow survival upon exposure to human blood phagocytes. Our data further indicate that relA contributes to the homeostatic transcriptional response to nutritional and oxidative/nitrosative stresses as it is required for amino acid biosynthesis in N. meningitidis (Fig. 5). Consequently, via variation in the GC content of the discriminator regions, the accumulation of (p)ppGpp during the stringent response might directly or indirectly contribute to the adapative regulation of genes required for energy metabolism, cell envelope biogenesis, translation and ribosome biogenesis and thus for large parts of the meningococcal transcriptome (Figs. 6 and 8). Furthermore, as the educt for Glu biosynthesis AKG provides a potential metabolic link between energy metabolism and the GSH cycle (Fig. 8) and was shown in $N$. meningitidis to contribute to, amongst others, the regulation of $\sigma^{\mathrm{E}}$ expression [87]. Since the expression of aniA was in turn shown to be under the negative control of $\sigma^{\mathrm{E}}$ [72], the finding that NO generated by AniA inhibits platelet aggregation [51] provides an exemplary 


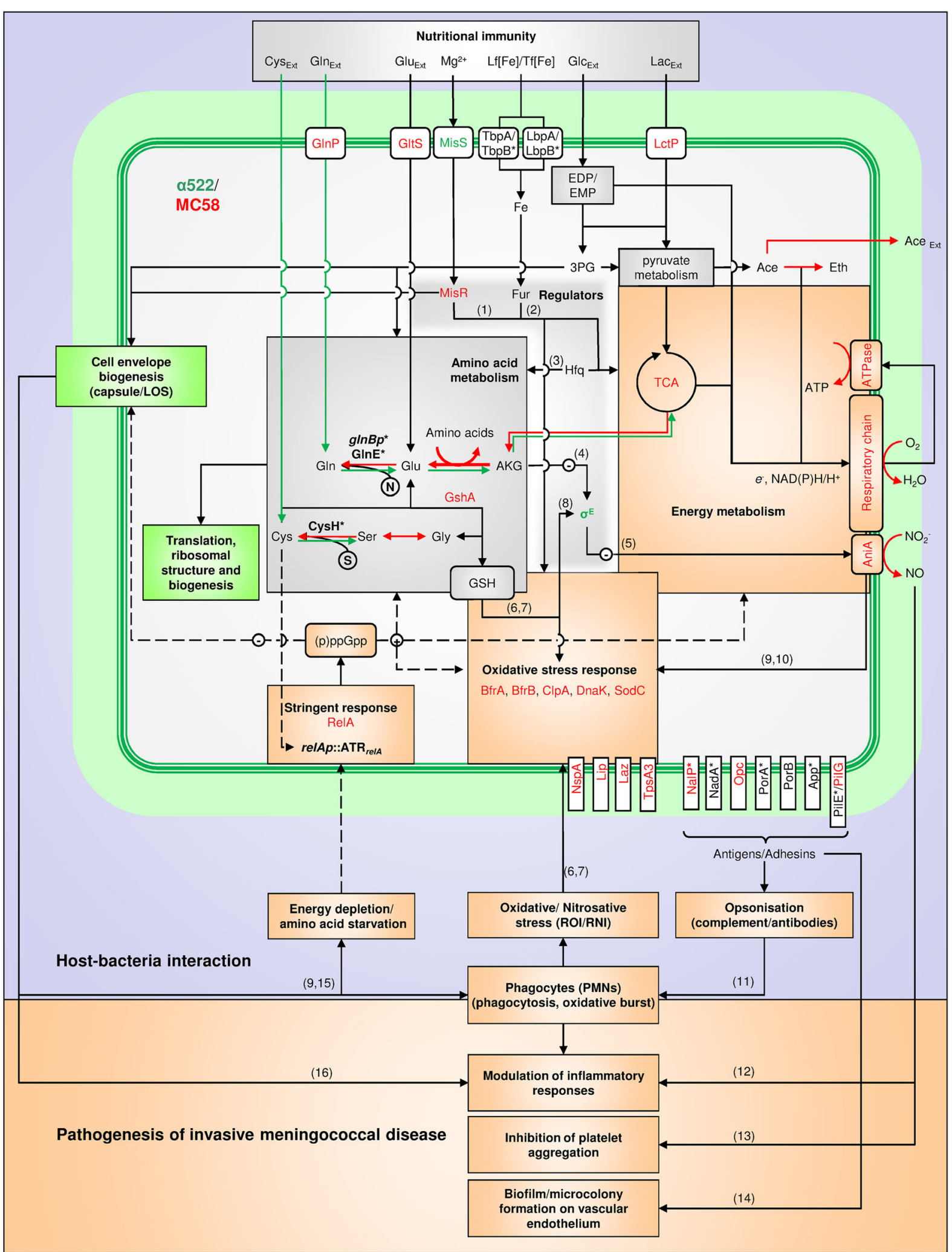

Fig. 8 (See legend on next page.) 


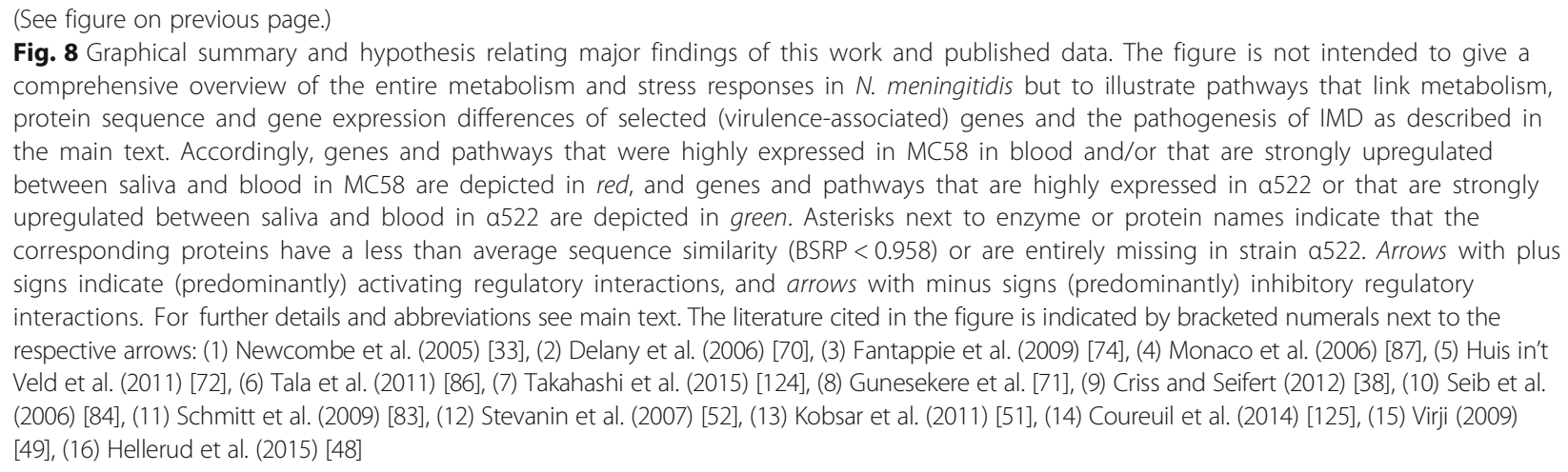

link between oxidative stress, Glu/Gln metabolism and the pathophysiology of meningococcal disease. In this picture, virulence, i.e. host damage, occurs coincidentally due to the transcriptional compensation of metabolic deficiencies by including genes with an established role in the pathogenesis of IMD. In consequence, meningococcal virulence is a byproduct of global stress and metabolic responses potentially triggered by human neutrophils and is dependent on the genetic background of the invading strain. In line with the recently proposed damage-response framework of microbial pathogenesis [88], we further hypothesize that strain-dependent differences in the interaction of meningococci with human neutrophils have a central role in explaining meningococcal virulence differences. However, a better systems biological understanding of the interaction of human phagocytes with meningococcal cells under infection relevant conditions has yet to be reached, and in addition to transcription [89] many other layers such as post-transcriptional modifications, allosteric regulation [90] and non-coding small RNAs [91] are likely to play an important role in metabolic regulation in meningococci.

The phenotypic similarity of both strains under the ex vivo conditions tested further indicate that most of genotypic variation observed in the genomic comparisons (Additional file 1: Figure S2) is likely cryptic for selection under conditions encountered by the species during its commensal life-cycle, and only upon an environmental perturbation these genotypic differences do result in different phenotypes. In evolutionary genetics, this so called cryptic genetic variation (CGV) describes the part of the genetic diversity that has the potential to affect the phenotype but that is not expressed under the current genotypic or environmental conditions which limits the opportunities for selection to act on the variation [35, 36]. However, under atypical conditions, rare in the history of a population, CGV can generate phenotypic variation. Human blood is a condition that is normally not encountered by meningococci during its commensal life cycle, and since bacteria replicating in the bloodstream are not transmitted to new hosts it has not been encountered by any ancestral meningococcal strain before. CGV might thus contribute to the high standing genetic variation observed in meningococcal population since the conditions that induce such allelic effects are rare in the history of the population, and IMD would therefore result from the accidental unmasking of meningococcal CGV in human blood. Furthermore, CGV is a subclass of variation with conditional effects, either in form of $G \times G$ or in $G \times E$ interaction. Accordingly, not only by environmental perturbation discussed above but also by genetic perturbation such as deletion of relA we could experimentally uncover CGV likely in genes required for amino acid biosynthesis and ex vivo fitness (Fig. 5). Loci with such pleiotropic effects known as genetic hubs or buffers are a common feature of the genetics of gene expression [26] and their existence emerges from the concept of CGV [36]. These genes are important for buffering both environmental change and stochastic variation thus ensuring environmental and stochastic resilience. Rather surprisingly, there have been only very few verified genetic hubs in published genetical genomics studies to date. Based on our observations and the published data on the physiology of the stringent response in, e.g., E. coli we hypothesize that it contributes to the phenotypic buffering of CGV in metabolic genes and that RelA in particular might constitute such a regulatory hub coincidentally affecting also meningococcal virulence. Therefore, the elucidation of the genetic variability and molecular mechanisms of stress responses in $N$. meningitidis will be important for the understanding of virulence evolution in this commensal pathogen. Of note, whereas the variability in the complement and/or sequence of genes coding for surface antigens and metabolic functions, respectively, among different meningococcal lineages and their potential role in meningococcal virulence have already been well established (e.g. ref. [92-95]), the extent of sequence variability in stress response genes and their possible 
contribution to virulence differences in meningococci have not been addressed so far. In addition, differences in intergenic regions affecting gene expression regulation [15] are often overlooked genetic determinants in the search for bacterial virulence factors. The impaired fitness of the $\alpha 522 \mathrm{ATR}_{\text {relA }}$ deletion mutant in human blood (Fig. 5) provides an example of how regulatory evolution via the integration of non-coding MITEs [79] into promoter regions might contribute to fitness and consequently virulence differences among bacterial strains in a condition-dependent manner.

As all experimental approaches for studying meningococcal infection biology this study has also its limitations. First, the ex vivo conditions chosen might not be truly representative for the in vivo situation. In particular, although meningococci have been found to be part of the normal flora of the oral cavity [96] they actually colonize the human nasopharynx where they immerse in the liquid produced by nasopharyngeal epithelium and constantly interact with epithelial cells. Therefore, saliva produced by saliva glands may not be truly representative of this commensal environment. Second, given their high genetic diversity [2] more meningococcal strains need to be compared in order to see how generalizable the transcriptomic results are with respect to the entire species. Furthermore, any microarray-based approach restricts the number of genes being compared to those represented on the microarray. Comparative transcriptome sequencing (RNA-Seq) approaches circumvent this limitation and will allow not only for the detection of expression differences in non-coding small RNAs [97] but, due to the higher dynamic range compared to microarrays [98], also for the detection of differences in genes expressed at very low and very high levels, respectively. Finally, as it was experimentally not possible to generate relA and spoT complemented strains for cis/trans complementation assays, the phenotypes of the relA and relA spoT deletion strains could in principle be also affected by polar effects of the gene disruption on adjacent genes. This needs to be addressed in further experimental studies.

In summary, the data presented in this work allow novel hypotheses to be generated regarding the genetic basis of meningococcal virulence differences. They in particular warrant detailed analyses of the interaction between meningococci and human neutrophils, the physiological consequences of sequence differences in cys $H$, $g \ln E$ or $g \ln B p$, the strain-dependent regulation of the stringent response in meningococci and how ATR might affect the expression of adjacent genes. The large transcriptomic data set provides per se an ex vivo gene expression compendium and as such a valuable resource for the meningococcal research community. Finally, our experimental approach further allows to challenge these findings in a larger panel of strains from carriage as well as hyperinvasive lineages and to seek for other genetic determinants affecting ex vivo fitness.

\section{Conclusion}

In the present work, we showed that despite identical ex vivo phenotypes two genetically similar strains of $N$. meningitidis displayed large differences in their transcriptomes including numerous virulence genes and subject to environmental conditions. Consequently, the often employed "model strain" approach might give misleading results in genetically diverse species like $N$. meningitidis which might not be representative for the entire species. Furthermore, the finding that relA is conditionally essential and likely contributes to the transcriptional buffering of cryptic genetic variation in metabolic genes potentially limits the universality of RelA as a novel drug target [99]. Finally, beyond the variation in the set of virulence genes observed in "model" bacterial pathogens such as E. coli, the finding that a short, non-coding repeat element affected meningococcal fitness in a strain- and condition-dependent manner highlights the importance also of regulatory evolution in the emergence of virulence in commensal pathogens. Together, these findings demonstrate that "to generalize results across genetic backgrounds, experiments must be carried out across genetic backgrounds" [25], and because the pathogenic nature of a microbe is a quantitative trait resulting from multiple interacting loci, with allelic effects that are sensitive to the environmental conditions, best within a systems biological framework. In this respect our experimental approach is generic for the identification of loci that are associated with the invasive phenotype also in other genetically diverse commensal pathogens.

\section{Methods}

\section{Strains and growth conditions}

N. meningitidis serogroup B strain $\alpha 522$ (ST-35 CC) was isolated from a healthy carrier in the course of the Bavarian Carriage Study [100], whereas strain MC58 (ST-32 CC) (Research Resource Identifier (RRID): SCR_002200) has been isolated from a case of invasive disease [101] (Table 1). Meningococcal strains were routinely grown on Columbia blood agar (bioMérieux, Nürtingen, Germany). Proteose peptone medium supplemented with Polyvitex (bioMérieux, Nürtingen, Germany) (PPM+) and RPMI 164020 mM HEPES (Biochrom AG, Berlin, Germany) were used to prepare liquid cultures of the meningococcal strains. E. coli strain TOP10 cells (Invitrogen, Darmstadt, Germany) were routinely cultivated on Luria-Bertani (LB) agar or LB broth at $37^{\circ} \mathrm{C}$. Kanamycin and chloramphenicol were added when required to select for the deletion mutants and complementing meningococcal strains at a final concentration of $100 \mu \mathrm{g} / \mathrm{ml}$ and $7 \mu \mathrm{g} / \mathrm{ml}$. Kanamycin 
and chloramphenicol were added at a final concentration of $30 \mu \mathrm{g} / \mathrm{ml}$ to select $E$. coli TOP10 strains during the cloning steps.

\section{In vitro growth experiments}

For the in vitro growth assays, strains were grown overnight at $37{ }^{\circ} \mathrm{C}$ and in $5 \% \mathrm{CO}_{2}$ on Columbia blood agar (bioMérieux). The next day, bacterial cells were inoculated in $\mathrm{PPM}+$, meningococcal minimal medium (MMM, adapted from refs. [85, 102]) or MMM supplemented with $2.10 \mathrm{mM} \mathrm{L}$-cysteine and further amino acids (Additional file 1: Figure S4) and grown at $37{ }^{\circ} \mathrm{C}$ with shaking at $200 \mathrm{rpm}$ on a laborytory shaker Certomat ${ }^{\bullet} \mathrm{H}$ (Braun Melsungen AG, Melsungen, Germany) for $1 \mathrm{~h}$. Bacterial cells were then adjusted to an optical density at $600 \mathrm{~nm}\left(\mathrm{OD}_{600}\right)$ of 0.1 using the WPA Biowave CO8000 Cell Density Meter (Biochrom Ltd., Cambridge, UK) and further cultivated at $37{ }^{\circ} \mathrm{C}$ and $200 \mathrm{rpm}$, and for each time point growth measurements were repeated three times.

\section{Adhesion and invasion assays}

Cell adhesion and invasion assays were performed with human $\mathrm{FaDu}$ (ATCC ${ }^{\ominus}$ number HTB-43 ${ }^{\mathrm{ma}}$, RRID: CVCL_1218) and Detroit 562 (CLS number 300399/ p754_Detroit-562, RRID: CVCL_1171) nasopharyngeal epithelial cell lines. The multiplicity of infection (MOI) was adjusted to 10 in RPMI 1640 and the cells were infected for $6 \mathrm{~h}$ at $37{ }^{\circ} \mathrm{C}$ with $5 \% \mathrm{CO}_{2}$. The numbers of adherent and intracellular bacteria were then assessed as described in [103]. All infection experiments were performed in duplicate and the experiments were repeated at least three times.

Lipooligosaccharide typing and serum bactericidal assays Lipooligosaccharide (LOS) immunotyping was performed using ELISA as described in [103]. Each serum bactericidal assay was repeated at least four times as described in [104].

\section{Sequencing and annotation of the N. meningitidis a522 genome}

For de novo sequencing of the $N$. meningitidis $\alpha 522$ genome at 79-fold coverage, Roche/454 sequencing of 3-kb paired-end libraries using the GS FLX Titanium chemistry (Roche Diagnostics, Penzberg, Germany) was combined with Sanger sequencing of fosmid libraries generated with vector pCC1FOS (EPICENTRE Biotechnologies, Madison, WI) and of PCR products for gap closure on an ABI 3730XL sequencer (Applied Biosystems, Foster City, CA). N. meningitidis $\alpha 522$ scaffolds and unscaffolded contigs were arranged according to the genome of the reference strain $N$. meningitidis MC58 (GenBank accession AE002098) using the Mauve Contig
Mover [105] and concatenated by 12-mer linkers (CTAGCTAGCTAG) containing stop codons in all six reading frames. The genome annotation system GenDB 2.0 [106] was used for automatic gene prediction and annotation of the $\alpha 522$ genome employing standard procedures. The final assembly of the $\alpha 522$ draft genome consisted of 21 contigs and comprised over $2.07 \mathrm{Mb}$ with about 2000 predicted coding sequences (Table 1).

\section{Computational genome analyses}

Genomes sequences were compared and visually inspected for manual data curation using Mauve [107] along with the Artemis Comparison Tool Release 5 [108] based on pairwise BLASTN alignments [109].

Orthologous genes were operationally defined as MC58 genes with a single significant best BLASTN hit in the $\alpha 522$ draft genome (E-value $<1 / 2000$ ), corresponding to at least $80 \%$ sequence identity over at least $90 \%$ of the sequence length. For pairwise coding sequence comparisons BLASTP bit score ratios (BSRP) were computed from the bit scores $\left(S^{\prime}\right)$ using MC58 coding sequences as query and either the significant best hit coding sequences from $\alpha 522$ (best hit) or MC58 (selfhit) as subject sequences according to $B S R=S_{\text {best hit }} /$ $S_{\text {self-hit }}$ as described in [110]. The encoded proteins were classified according to the COG functional classification scheme [37], and functional domains were assigned using NCBI's Conserved Domain Database (CDD) [111]. We further used PSORTb 3.0 for the prediction of the subcellular localization of the encoded proteins [112].

Discriminative motif discovery was performed using MEME version 4.8.1 [113] to identify overrepresented bona fide TF binding sites within 200 bp regions upstream of predicted ATG translational start codons among differently expressed gene sets and with a minimum motif width of $2 \mathrm{bp}$ and a maximum of $50 \mathrm{bp}$, respectively. Shuffleseq from the EMBOSS software package [114] was used for the randomization of $200 \mathrm{bp}$ upstream sequences. ATR sequences together with the adjacent up- and downstream $10 \mathrm{bp}$ were extracted from the original Z2491 genome annotation published in ref. [115]. Consecutively, the ATR consensus sequence obtained from a multiple sequence alignment with MUSCLE [116] was used for similarity searches in the genomes of MC58 and $\alpha 522$ with BLASTN [109], and promoter prediction in the $\operatorname{gr} x B$ - relA intergenic region was carried using a neural network approach as implemented in PPP [117].

\section{Collection and processing of human specimens}

Donors for saliva and blood were selected based on (a) not having a history of vaccination against $N$. meningitidis serogroups $\mathrm{A}, \mathrm{B}, \mathrm{C}, \mathrm{W}$ and $\mathrm{Y}$, respectively, (b) not having taken any antibiotics within 5 days prior sampling, and (c) not currently being carriers of 
meningococci. Human saliva was collected from the donors after stimulation with CRT paraffin (Ivoclar Vivadent $\mathrm{GmbH}$, Ellwangen, Germany). The collected saliva was processed via centrifugation at $4000 \mathrm{rpm}$ for $10 \mathrm{~min}$ followed by filter sterilization using $0.2 \mu \mathrm{m}$ filters (Sarstedt, Nümbrecht, Germany) to eliminate all bacterial and eukaryotic host cells from the sample. Human CSF samples were obtained from the routine diagnostic laboratory at the Institute for Hygiene and Microbiology of the University of Würzburg and tested for sterility and the absence of antibiotics as well as leucocytes according to established standard operating procedures. The CSF and saliva samples were pooled and stored at $-20{ }^{\circ} \mathrm{C}$. Prior to the experiment, the pooled CSF samples were gassed with $\mathrm{CO}_{2}$ and $\mathrm{pH}$ was controlled to be in the physiologic range between $\mathrm{pH} 7.0-7.5$. Heparinized human venous blood from four healthy donors (two males and two females) was drawn fresh on the day of the experiment and was used within an hour of collection.

\section{Ex vivo survival assays}

Before exposure to human saliva, blood and cerebrospinal fluid bacterial strains were grown in PPM+ medium to mid log phase $\left(\mathrm{OD}_{600 \mathrm{~nm}} \sim 0.5-0.6\right)$. One milliliter of the culture was harvested by centrifugation and after washing with $1 \mathrm{x}$ PBS, the bacterial pellet was resuspended in $1 \mathrm{ml}$ of $1 \mathrm{x}$ PBS. Ten microliter of this suspension corresponding to $\sim 10^{6}$ colony forming units $(\mathrm{cfu}) / \mathrm{ml}$ were inoculated into $1 \mathrm{ml}$ of human saliva, blood and cerebrospinal fluid, respectively, and incubated at $37{ }^{\circ} \mathrm{C}$ with shaking. Aliquots were taken out after $30 \mathrm{~min}, 60 \mathrm{~min}$ and $120 \mathrm{~min}$ and serial dilutions were plated out on Columbia blood agar (bioMérieux) to estimate the number of viable bacteria. Ex vivo infection experiments with human saliva and human CSF were performed using pooled saliva and pooled CSF samples, respectively, whereas ex vivo infections using whole venous blood were performed individually with each of the four blood samples and the isolated bacterial RNAs were pooled prior further analysis.

\section{Isolation of bacterial RNA}

The meningococcal strains were grown in PPM+ medium to mid log phase $\left(\mathrm{OD}_{600 \mathrm{~nm}} \sim 0.5-0.6\right)$, harvested by centrifugation and the bacterial pellets were resuspended in equal volumes of pooled saliva, pooled CSF and whole venous blood, respectively. To detect transcriptional differences in both strains independent of the exposure to human material $\mathrm{PPM}+$ medium was used as control, and all samples were incubated at $37^{\circ} \mathrm{C}$ with $5 \% \mathrm{CO}_{2}$ for $30 \mathrm{~min}$. Bacterial cells exposed to $\mathrm{PPM}+$, pooled saliva and pooled CSF, respectively, were harvested by centrifugation at $4000 \mathrm{rpm}$ for
10 min and shock frozen in liquid nitrogen for RNA isolation. Blood suspensions containing bacteria were centrifuged at $1000 \mathrm{rpm}$ for $10 \mathrm{~min}$ to allow the blood cells to settle down, and the supernatant containing the bacterial cells were transferred to a fresh tube and harvested by centrifugation at $4000 \mathrm{rpm}$ for $10 \mathrm{~min}$. The pellets were then washed with erythrocyte lysis buffer (Qiagen, Hilden, Germany) and the bacterial pellet was shock frozen in liquid nitrogen for further RNA isolation. From the bacterial pellets, total RNA was isolated using TRIZOL $^{\circ}$ (Invitrogen $\mathrm{GmbH}$, Darmstadt, Germany) according to the manufacturer's protocol with slight modifications with respect to bacterial cell lysis. Contaminating DNA was removed by treating the samples with DNAse (Applied Biosystems) according to the manufacturer's protocol. Absence of meningococcal chromosomal DNA was verified by PCR for the MLST housekeeping genes fum $C$ and $a d h$. Absence of contaminating host DNA was confirmed by PCR using primers Act- 1 and Act- 2 for the eukaryotic $B$ actin gene. Quality analysis of the RNA was performed using the Agilent 2100 Bioanalyzer (Agilent Technologies, Böblingen, Germany) and the RNA integrity factor was controlled to be $>7$ in all cases as described by the manufacturer. All experiments were performed in triplicate to yield three RNA samples (replicates) for each strain under the four ex vivo conditions, and intact total RNA could be obtained for both strains and all conditions at 30 min of incubation (Additional file 1: Figure S7A and B).

\section{Microarray hybridization and data analysis}

We used a spotted 70-mer oligonucleotide microarray comprising, amongst others, all 2063 open reading frames of $N$. meningitidis strain MC58 (GenBank AE002098). The layout of the microarray has been deposited in NCBI's Gene Expression Omnibus database (http://www.ncbi.nlm.nih.gov/geo/) and is accessible through the GEO series accession number GPL9200. To allow for all possible pairwise comparisons of gene expression profiles we chose a common reference experimental design, and aliquots from each of the 24 RNA samples (isolated from the two strains under the four ex vivo conditions with three replicates each as described above) were pooled to form the common reference. Probe labeling, slide hybridization and analyses of raw data were performed as previously described [118] using a Tecan HS 4800 Pro hybridization station (Tecan Deutschland GmbH, Crailsheim, Germany) and a Genepix professional 4200A scanner (MDS Analytical Technologies, Ismaning, Germany) with the Genpix Pro 6.0 gridding software. Briefly, spots that were automatically reported as "Bad" or "Not found" by the Genepix Pro software were flagged and ignored during further processing. Likewise, spots that had a signal to noise ratio 
of $<3$ were manually flagged as "Bad" and also ignored during subsequent analysis. The resulting raw data files were processed using the loess method for within slide normalization and the rquantile method for between slide normalization implemented in the $\mathrm{R}$ language [119] package Limma of the Bioconductor software project [120].

For further analyses, two data sets were generated both comprising 24 microarrays, one for the analysis of transcriptional changes only within strain MC58, and a second one for the comparison of the transcriptomes between strain MC58 and strain $\alpha 522$. The first dataset comprised almost the entire gene complement of strain MC58. However, due particularly to the presence of multiple, almost identical copies of the filamentous prophage Nf and a large duplication in the MC58 genome which both result in extensive within-genome cross homologies, it was not possible to design specific oligo probes for 76 genes. Consequently, to assess the transcriptional changes in strain MC58 only 1987 open reading frames were used and the resulting coverage is therefore 96.3\% (1987/2063) with respect to the Genbank annotation AE002098. The second dataset was designed to specifically analyze transcriptional differences between both strains taking into account possible confounding effects due to sequence differences in orthologous genes and/or differences in the gene dosage between both strains. Both factors might affect the hybridization signal intensities of the respective oligo probes in microarray comparisons. Therefore, for transcriptome comparisons between both strains we selected only those genes and corresponding oligo probes, respectively, which met the following criteria: (i) all genes in MC58 used for transcriptome comparisons must have a single unique best BLASTN self-hit in the MC58 genome and a single unique best BLASTN hit in the $\alpha 522$ genome to exclude paralogous genes; (ii) the ratio between the BLASTN bit scores of their best hit in the $\alpha 522$ genome and of the respective MC58 gene self-hits must be greater than 0.6 to also exclude truncated CDSs; (iii) all oligo probes must have been found to hybridize with both genomes in a recently performed comparative genome hybridization study including both strains [28]; and (iv) all oligo probes must hit the orthologous genes in both genomes with fewer than eight mismatches over their entire length ( $>90 \%$ sequence identity). These criteria allowed us to examine the expression profile of 1450 genes between the two strains and in the four different ex vivo conditions using the limma package. We confirmed that there was no correlation between (absolute) gene expression level differences among strains and the percent sequence identity of the MC58 based oligonucleotides with their respective targets in the $\alpha 522$ draft genome ( $p_{\text {Pearson }}>0.1$, Additional file 1 :
Figure S7C), thus avoiding any strain bias in the expression data. Comparison of the expression levels of sixteen genes in PPM+, saliva, blood and CSF further revealed a good correlation between the microarray and the corresponding qRT-PCR data ( $n=43$ measurements, Person's adjusted $R^{2}=0.74$, pearson $\left.<10^{-13}\right)$. All expression data are given in Additional file 2: S1.

\section{Assessment and analysis of significantly differently expressed genes}

Using limma, only genes having a false discovery rate $($ FDR $)<0.05$ after applying the Benjamini-Hochberg (BH) multiple testing correction and a log-odds (B-statistic) $>3$, corresponding to a greater than $95 \%$ probability of being differentially expressed, were included in further data analyses. Overrepresentation analyses were performed using a contingency table and Fisher's exact test to assess whether a COG functional category [37] was overrepresented among differently expressed genes. Unless stated otherwise, for all comparisons of multiple genes sets the Benjamini-Hochberg multiple testing correction was used with a FDR cut-off of 0.05 .

\section{Metabolic reconstructions of strain MC58 and a522}

The metabolic network of strain MC58 was reconstructed based on genes and reactions from the Nmb_iTM560 model [55], missing reactions were added according to references and KEGG database (Neisseria meningitidis MC58, serogroup B model). Futile cycles were eliminated and redundant reactions were removed from the collection, to derive a condensed network applicable for direct flux balance analysis (full simulation, not just sampling of modes). The generated model comprised 123 gene-associated enzymes and 129 metabolites involved in glycolysis, the pentose phosphate pathway and the TCA cycle. Furthermore, intermediary metabolism included lactate, acetate and acetoacetate metabolism, as well as amino acid metabolism, glutathione metabolism, purine and pyrimidine metabolism. Uptake transporters were taken into account if the metabolite appeared either in the composition list of human saliva or human blood as taken from ref. [58]. Network reconstruction was accomplished using the YANAsquare software [56]. A metabolic model for strain $\alpha 522$ was constructed in the same way, noting minor differences in metabolism (see results for details).

\section{Flux balance analysis of transcriptomic data}

Flux computation was carried out by the YANAvergence package [57] and the Nmb_iTM560 metabolic model [55] modified as described above to get all the extreme pathways which describe the steady-state solution space of this genome-scale metabolic network. We used the normalized gene expression data 
described above to determine the corresponding enzyme activities encoded by genes that showed significant expression differences between both strains in saliva and blood, respectively. The activity of an enzyme complex comprised by different subunits was defined by the average intensity of the corresponding subunits, whereas the activity of a reaction catalyzed by isoenzymes was determined by the total activities of these encoding genes. Once convergence was reached, we used the estimated flux distribution to compute all the unmeasured enzyme activities. Finally, the enzyme activities computed according to our model were either compared between two conditions for strain MC58 or between both strains in human blood to investigate obvious differences.

\section{Protein-protein interaction network analysis of transcriptomic data}

Protein-protein interaction network data for the core genome of $N$. meningitidis strain MC58 have been extracted from the STRING database (version 9.0, http:// string-db.org) [54] yielding a total of 149,957 interactions between 2.052 genes. Based on the edge probabilities of the STRING database two microarray-specific networks of medium (probability $>0.4$ ) and high confidence (probability $>0.7$ ) have been derived. For the integrated network analysis the largest connected component of both networks have been used, comprising 21,071 interactions between 1,200 genes (medium confidence) and 4,360 interactions between 783 genes (high confidence). For all contrasts of interest $p$-values have been derived from the limma analyses. For the integrated network analysis node (gene) scores have been computed based on these $p$-values as detailed in [53] using the routines implemented in the R-package BioNet [121].

\section{Quantitative real-time RT-PCR}

Validation of the microarray data was performed using the StepOnePlus ${ }^{\mathrm{TM}}$ Real-Time PCR system with SYBRGreen (Applied Biosystems) as described in [122]. Briefly, $2 \mu \mathrm{g}$ of DNA free RNA were reverse transcribed and suitable dilutions of the cDNA were used as template for quantification using the StepOnePlus ${ }^{\mathrm{Tw}}$ RealTime PCR system. The relative amounts of the cDNAs in the various samples were determined using the comparative CT method as described by the manufacturer. NMB1592 and rpoC which were not found to be differentially regulated under any of the conditions tested in this study by the microarray experiment were used as housekeeping genes for relative quantification of the investigated genes. All oligonucleotides used in this study are listed in Additional file 1: Table S2.
Transcriptional start site mapping of relA with 5' RACE The transcriptional start site (TSS) of relA and $g r x$ in the strains MC58 and $\alpha 522$ was determined using the 5'/3' RACE Kit, $2^{\text {nd }}$ Generation (Roche Applied Science, Manheim, Germany) according to manufacturer's protocol. Briefly, cDNA was prepared using DNA free RNA from both the strains with a gene specific primer (relAGSP1 for relA and grxGSP1 for $g r x$ ) and the reagents of the 5'/3' RACE Kit. After incorporation of the poly(A) tail at the $5^{\prime}$ end of the cDNA using the Terminal Transferase in the 5'/3' RACE Kit, the tailed cDNA was amplified by PCR using the Oligo(dT) Anchor Primer along with primers relAGSP2 and grxGSP2 for relA and $\operatorname{grxB}$, respectively (Additional file 1: Table S2). Both are nested primers which bind internal on the cDNA generated by relAGSP1 and grxGSP1 primer. After confirmation of the presence of a pure fragment of the expected size by agarose gel electrophoresis, the DNA fragment was purified using Qiagen PCR purification kit (Qiagen, Hilden, Germany) and sequenced on a ABI PRISM ${ }^{\circ} 3130$ Genetic Analyzer (Applied Biosystems) using standard BigDye ${ }^{\bullet}$ Terminator v1.1 cycle sequencing chemistry (Applied Biosystems) to identify the transcriptional start site of the $r e l A$ and $g r x B$ in both strains independently.

\section{Construction of isogenic deletion and insertion mutants}

Deletion mutants were generated in the genetic background of $N$. meningitidis strain MC58 and $\alpha 522$ by replacing the entire encoding sequence with a kanamycin or a chloramphenicol resistance cassette (Additional file 1: Figure S6). Approximately 600 bp fragments of the flanking regions of the target genes were amplified by PCR from N. meningitidis MC58 and $\alpha 522$ genomic DNA, respectively. Primers used for generation of flanking regions (upand downstream) of target genes are listed in Additional file 1: Table S2. Up- and downstream regions were created with different restriction sites. Flanking regions were amplified with Q5 high fidelity polymerase (NEB, Frankfurt, Germany), purified, digested and ligated into the pBluescript (pBS-KS, Stratagene, Heidelberg, Germany). Constructs were moved into E. coli TOP10 cells (Invitrogen) using chemical transformation technique. Deletion of the AT rich repeat region in the $5^{\prime}$ region of relA in strain $\alpha 522$ was achieved by restriction free cloning using megaprime PCR. Around $600 \mathrm{bp}$ regions upstream and downstream of the ATR in $\alpha 522$ were amplified using oligonucleotides where the 3'oligonucleotide of the upstream fragment had a complementarity of about $25 \mathrm{bp}$ to the 5 'region of the downstream fragment and similarly the 5 'oligonucleotide of the downstream fragment had a complementarity of about $25 \mathrm{bp}$ to the 3'region of the upstream fragment. These two purified fragments were further used as template for a fusion PCR to yield a fused DNA fragment containing the upstream and downstream regions of the ATR in strain 
$\alpha 522$. This fusion fragment was cloned into the pBluescript cloning vector, then transformed into strain $\alpha 522$ and deletion of the ATR in the mutant strain was confirmed by PCR and sequencing.

The insertion of the AT rich repeat region in the 5' region of relA in strain MC58 was also achieved by restriction free cloning using megaprime $\mathrm{PCR}$, as described above. Corresponding oligonucleotides were listed in Additional file 1: Table S2. The resulting PCR fusion fragment was then ligated into pBS-SK, cloned into strain MC58 and insertion of the ATR in the mutant strain was confirmed by PCR and sequencing.

The same method was used to create $\operatorname{grx} B$ deletion mutants in strain $\alpha 522$ and MC58 (Additional file 1: Figure S7A). Around 600 bp upstream and downstream of $\operatorname{grxB}$ were amplified, fused by megaprime PCR to a chloramphenicol resistance cassette and ligated into cloning vector pBS-SK. The resulting plasmid, listed in Additional file 1: Table S3, was then transformed into strain $\alpha 522$ and MC58.

All plasmids used to generate the deletion and insertion mutants are listed in Additional file 1: Table S3. Naturally competent MC58 and $\alpha 522$ cells were transformed and selected on GC agar plates containing kanamycin and/or chloramphenicol. The resulting mutants and meningococcal isolated were listed in Additional file 1: Table S4. The correct insertion of the resistance cassettes was confirmed by PCR and sequencing as well as by southern blot analysis using Hybond N+ nylon membranes (GE Healthcare, Munich, Germany) and the DIG DNA labeling and detection kits (Roche Applied Science, Mannheim, Germany) according to the manufacturer's instructions.

\section{ppGpp extraction and quantification}

Strains were grown over night at $37{ }^{\circ} \mathrm{C}$ and in $5 \% \mathrm{CO}_{2}$ on blood agar plates. The next day, bacterial cells were preincubated in PPM+ medium at $37{ }^{\circ} \mathrm{C}$ and $200 \mathrm{rpm}$ for $45 \mathrm{~min}$, the optical density adjusted to $\mathrm{OD}_{600 \mathrm{~nm}}=0.1$ and the bacteria cultured at $37{ }^{\circ} \mathrm{C}$ and $200 \mathrm{rpm}$ in $50 \mathrm{ml}$ of $\mathrm{PPM}+$ medium. At $\mathrm{OD}_{600 \mathrm{~nm}}$ values of 0.5 - 0.6 (mid log, $1.5 \mathrm{~h}$ ) and $\leq 1.6$ (late $\log , \sim 4-5 \mathrm{~h}$ ) the cells were harvested via centrifugation at $4{ }^{\circ} \mathrm{C}$ and $4000 \mathrm{rpm}$ for $10 \mathrm{~min}$ in a Heraeus Megafuge 1.0 R (Thermo Scientific) centrifuge. The pellets were subsequently shock-frozen in liquid nitrogen and stored at $-80{ }^{\circ} \mathrm{C}$. For subsequent ppGpp extraction the pellets were resuspended in $1.25 \mathrm{ml}$ of ice-cold $2 \mathrm{M}$ formic acid and incubated on ice for $30 \mathrm{~min}$. These samples were subsequently centrifuged at $4{ }^{\circ} \mathrm{C}$ at $4000 \mathrm{rpm}$ for $10 \mathrm{~min}$ and the supernatant filtered through a $0.2 \mu \mathrm{m}$ filter and stored at $-20{ }^{\circ} \mathrm{C}$ until use.

For HPLC analyses, a Smartline HPLC system with a flow rate of $1.3 \mathrm{ml} / \mathrm{min}$. The samples were loaded under initial conditions of $95 \%$ of solution A (Tris- $\mathrm{HCl} 20 \mathrm{mM}$, $\mathrm{pH}$ 8) and $5 \%$ of solution $\mathrm{B}$ (Tris- $\mathrm{HCl} 20 \mathrm{mM}$, sodium formiat, $1.5 \mathrm{M}, \mathrm{pH}$ 8) for $20 \mathrm{~min}$. Then the solution B was ramped up to $60 \%$ during $45 \mathrm{~min}$. The column was washed with $100 \%$ of solution B for $10 \mathrm{~min}$ and finally equilibrated with $95 \%$ of A and 5\% B for 15 min. Quantification was performed using the ChromGate V3.3.2 software (Knauer, Berlin, Germany). The ppGpp standard was purchased from Trilink Biotechnologies. Standard curves were established using a total of ten different ppGpp concentrations ranging from 20 to $10000 \mathrm{pmol}$.

\section{Additional files}

Additional file 1: Contains supplemental results and discussion describing the results of ex vivo cross-condition gene expression comparisons in strain MC58 along with the corresponding supplemental references and the figure legends to the supplemental Figures $\mathbf{S} \mathbf{1}$ to $\mathbf{S} 8$ as well as the supplemental Tables S1 to S4. Figure S1. Experimental setup of the study. Figure S2. Comparison of the N. meningitidis a522 and MC58 genomes. Figure S3. qRT-PCR validation of ex vivo cross-strain expression differences in selected putative virulence-associated and regulatory genes. Figure S4. Growth of strain a522 in minimal medium supplemented with different combinations of amino acids. Figure S5. Comparison of the stringent response in N. meningitidis strain MC58 and a522. Figure S6. Genetic map of the relA and spoT loci in the mutant strains. Figure S7. Quality assessment of total RNA and microarray data. Figure S8. Discriminator regions in genes differently expressed in different ex vivo conditions in MC58. Table S1. Strain a522 specific genes. Table S2. Oligonucleotides used in this study. Table S3. Plasmids used in this study. Table S4. Strains used in this study. (ZIP 19627 kb)

Additional file 2: $\mathrm{S} 1$ is an Excel spread sheet containing the MC58 genome annotation data together with the results of the pairwise genome comparison with a522 and the microarray data. (XLSX $418 \mathrm{~kb}$ )

Additional file 3: $S 2$ is an Excel spread sheet containing the results of the elementary mode analyses in human blood based on MC58 metabolic network model. (XLSX $18 \mathrm{~kb}$ )

\section{Abbreviations}

(p)ppGpp: Guanosine pentaphosphate or tetraphosphate; 3PG: 3-Phosphoglyceric acid; ACA: Acetaldehyde; AcCoA: Acetyl coenzyme A; ACE: Acetate; ADP: Adenosine diphosphate; AKG: a-ketoglutarate; ATP: Adenosine triphosphate; ATR: AT-rich; BH: Benjamini-Hochberg; bp: Base pair; BSRN: BLASTN bit score ratio; BSRP: BLASTP bit score ratio; CCs: Clonal complexes; CDD: Conserved domain database; CDS: Coding DNA sequence; CFU: Colony-forming units; CGV: Cryptic genetic variation; CHOR: Chorismate; $\mathrm{Cl}$ : Confidence interval; CIT: Citrate; $\mathrm{CO}_{2}$ : Carbon dioxide; CoA: Coenzyme A; COG: Cluster of orthologous groups; CSF: Cerebrospinal fluid; Cys/CYS : Cysteine; ED: Entner-Doudoroff; EM: Elementary mode; ETH: Ethanol; ext: External; FDR: False discovery rate; G x E: Gene-environment interaction; G x G: Genegene interaction; GC content: Guanine-cytosine content; Gln/GLN: L-glutamine; Glu/GLU: L-glutamate; Gly/GLY: Glycine; GSA: Gene set enrichment analysis; GSH: Glutathione; $\mathrm{H}$ : Hydrogen; $\mathrm{H}_{2} \mathrm{~S}$ : Hydrogen sulfide; $\mathrm{HS}^{-}$: Bisulfide; IMD: Invasive meningococcal disease; IVA: Oxoisovalerate; LB: Luria-Bertani; Leu/LEU: Leucine; LOS: Lipooligosaccharide; LOS: Lipooligosaccharide; MITEs: Miniature inverted-repeat transposable-elements; MLST: Multilocus sequence typing; MMM: Meningococcal minimal medium; MOl: Multiplicity of infection; $N(0)$ : Is the initial quantity, at time $t=0 ; N(t)$ : Quantity at time t; $\mathrm{N}$ : Cell number; n: Number; NAD: Nicotinamide adenine dinucleotide; NADH: Reduced NAD; NADP: Nicotinamide adenine dinucleotide phosphate; $\mathrm{NADPH}$ : Reduced NADP; $\mathrm{NH}_{3}$ : Ammonia; $\mathrm{NO}$ : Nitric oxide; $\mathrm{O}_{2}$ : Oxygen; $\mathrm{OD}_{600}$ : Optical density at $600 \mathrm{~nm}$; OR: Odds ratio; OXA: Oxaloacetate; $p$ : $p$-value; PC: Phylogenetic clade; PEP: Phosphoenolpyruvate; Phe/PHE: Phenylalanine; PPI: Protein-protein interaction; PPM+: Proteose peptone medium supplemented with Polyvitex; PRE: Prephenate; $R^{2}$ : Linear regression; RBS: Ribosome binding site; $\mathrm{S}^{\prime}$ : Bit score; Ser/SER: Serine; $\mathrm{SO}_{3}$ : Sulfur trioxide; STs: Sequence types; t: Time point; TCA: Tricarboxylic acid; TF: Transcription factors; THS: Thiosulfate; TSS: Transcriptional start site; Tyr/TYR: Tyrosine 


\section{Acknowledgements}

We thank Gabriele Gerlach and Kay Johswich for reading the manuscript and helpful suggestions.

\section{Funding}

The work was supported by the German Research Foundation (DFG) grants SCHO 1322/1-1 to CS, TR34/A8 to TD and CL, and the FungiNet grant TR124/B2 to MD.

\section{Availability of data and materials}

The nucleotide sequence of the N. meningitidis a522 draft assembly was submitted to the European Nucleotide Archive (http://www.ebi.ac.uk/ena) and is retrievable under the accession numbers FR845693 to FR845718. The microarray gene expression data associated with this study has been deposited in NCBl's Gene Expression Omnibus (http://www.ncbi.nlm.nih.gov/ geo/) and are accessible through the GEO series accession number GSE38051. All other data generated or analysed during this study are included in this published article and its Additional file 1.

\section{Authors' contributions}

BJA and LK conducted the microarray, PCR and growth experiments and constructed all mutant strains of this work. $C L$ and TD performed the elementary and flux balance analyses. MD and TM performed the PPI network analyses. AS, JB and AG sequenced, assembled and annotated the a522 genome. EK and AB made the pppGpp measurements. CS designed the study, analysed the data and wrote the paper. All authors read and approved the final manuscript.

\section{Competing interests}

The authors declare that they have no competing interests.

\section{Consent for publication}

Not applicable

\section{Ethics approval and consent to participate}

The ethics committee at the Medical Faculty of the University of Würzburg approved the study and the use of human saliva and whole blood from adult volunteers as well as the use of pooled human CSF samples obtained from patients with no history of acute bacterial meningitis (reference number 237/10). Written, informed consent was obtained from the saliva and blood donors.

\section{Publisher's Note}

Springer Nature remains neutral with regard to jurisdictional claims in published maps and institutional affiliations.

\section{Author details \\ ${ }^{1}$ Institute for Hygiene and Microbiology, Joseph-Schneider-Straße 2 , University of Würzburg, 97080 Würzburg, Germany. ${ }^{2}$ Department of Bioinformatics, Biocenter, University of Würzburg, Am Hubland, 97074 Würzburg, Germany. ${ }^{3}$ Department of Human Genetics, Biocenter, University of Würzburg, Am Hubland, 97074 Würzburg, Germany. ${ }^{4}$ Center for Biotechnology (CeBiTec), Bielefeld University, Universitätsstr. 27, 33615 Bielefeld, Germany. ${ }^{5}$ Institute for Bioinformatics and Systems Biology, Justus Liebig University Gießen, Heinrich-Buff-Ring 58, 35392 Gießen, Germany. ${ }^{6}$ LOEWE-Center for Synthetic Microbiology, Hans-Meerwein-Straße, 35032 Marburg, Germany.}

\section{Received: 24 August 2016 Accepted: 10 March 2017} Published online: 07 April 2017

\section{References}

1. The Human Microbiome Project Consortium. Structure, function and diversity of the healthy human microbiome. Nature. 2012;486(7402):207-14.

2. Caugant DA, Maiden MC. Meningococcal carriage and disease - population biology and evolution. Vaccine. 2009;27 Suppl 2:B64-70.

3. Herrick WW. Extrameningeal meningococcus infections. Arch Intern Med. 1919;23(4):409-18

4. Stephens DS, Greenwood B, Brandtzaeg P. Epidemic meningitis, meningococcaemia, and Neisseria meningitidis. Lancet. 2007;369(9580): 2196-210.

5. Pallen MJ, Wren BW. Bacterial pathogenomics. Nature. 2007:449(7164):835-42.
6. Falkow S. Molecular Koch's postulates applied to microbial pathogenicity. Rev Infect Dis. 1988;10 Suppl 2:S274-6.

7. Schoen C, Tettelin H, Parkhill J, Frosch M. Genome flexibility in Neisseria meningitidis. Vaccine. 2009;27 Suppl 2:B103-11.

8. Marri PR, Paniscus M, Weyand NJ, Rendon MA, Calton CM, Hernandez DR, Higashi DL, Sodergren E, Weinstock GM, Rounsley SD, et al. Genome sequencing reveals widespread virulence gene exchange among human Neisseria species. PLoS One. 2010;5(7):e11835.

9. Buckee CO, Jolley KA, Recker M, Penman B, Kriz P, Gupta S, Maiden MC. Role of selection in the emergence of lineages and the evolution of virulence in Neisseria meningitidis. Proc Natl Acad Sci U S A. 2008;105(39): 15082-7.

10. Schoen C, Kischkies L, Elias J, Ampattu BJ. Metabolism and virulence in Neisseria meningitidis. Front Cell Infect Microbiol. 2014;4:114.

11. Perez JC, Groisman EA. Evolution of transcriptional regulatory circuits in bacteria. Cell. 2009;138(2):233-44.

12. Lozada-Chavez I, Janga SC, Collado-Vides J. Bacterial regulatory networks are extremely flexible in evolution. Nucleic Acids Res. 2006;34(12):3434-45.

13. Madan Babu M, Teichmann SA, Aravind L. Evolutionary dynamics of prokaryotic transcriptional regulatory networks. J Mol Biol. 2006;358(2):614-33.

14. Blount ZD, Barrick JE, Davidson CJ, Lenski RE. Genomic analysis of a key innovation in an experimental Escherichia coli population. Nature. 2012; 489(7417):513-8.

15. Oren $Y$, Smith MB, Johns NI, Kaplan Zeevi M, Biran D, Ron EZ, Corander J, Wang HH, Alm EJ, Pupko T. Transfer of noncoding DNA drives regulatory rewiring in bacteria. Proc Natl Acad Sci U S A. 2014; 111(45):16112-7.

16. Winfield MD, Groisman EA. Phenotypic differences between Salmonella and Escherichia coli resulting from the disparate regulation of homologous genes. Proc Natl Acad Sci U S A. 2004;101(49):17162-7.

17. Mandel MJ, Wollenberg MS, Stabb EV, Visick KL, Ruby EG. A single regulatory gene is sufficient to alter bacterial host range. Nature. 2009; 458(7235):215-8

18. Escobar-Paramo P, Clermont $\mathrm{O}$, Blanc-Potard AB, Bui H, Le Bouquenec $\mathrm{C}$, Denamur E. A specific genetic background is required for acquisition and expression of virulence factors in Escherichia coli. Mol Biol Evol. 2004;21(6): 1085-94.

19. Methot PO, Alizon S. What is a pathogen? Toward a process view of hostparasite interactions. Virulence. 2014;5(8):775-85.

20. Price MN, Deutschbauer AM, Skerker JM, Wetmore KM, Ruths T, Mar JS, Kuehl JV, Shao W, Arkin AP. Indirect and suboptimal control of gene expression is widespread in bacteria. Mol Syst Biol. 2013;9:660.

21. Echenique-Rivera $H$, Muzzi A, Del Tordello $E$, Seib KL, Francois $P$, Rappuoli R, Pizza M, Serruto D. Transcriptome analysis of Neisseria meningitidis in human whole blood and mutagenesis studies identify virulence factors involved in blood survival. PLoS Pathog. 2011;7(5): e1002027.

22. Hedman AK, Li MS, Langford PR, Kroll JS. Transcriptional profiling of serogroup B Neisseria meningitidis growing in human blood: an approach to vaccine antigen discovery. PLoS One. 2012;7(6):e39718.

23. Exley RM, Shaw J, Mowe E, Sun YH, West NP, Williamson M, Botto M, Smith $\mathrm{H}$, Tang CM. Available carbon source influences the resistance of Neisseria meningitidis against complement. J Exp Med. 2005;201(10): 1637-45.

24. Metruccio MM, Pigozzi E, Roncarati D, Berlanda Scorza F, Norais N, Hill SA, Scarlato V, Delany I. A novel phase variation mechanism in the meningococcus driven by a ligand-responsive repressor and differential spacing of distal promoter elements. PLoS Pathog. 2009;5(12):e1000710.

25. Civelek M, Lusis AJ. Systems genetics approaches to understand complex traits. Nat Rev Genet. 2014;15(1):34-48.

26. Rockman MV, Kruglyak L. Genetics of global gene expression. Nat Rev Genet. 2006;7(11):862-72.

27. Budroni S, Siena E, Dunning Hotopp JC, Seib KL, Serruto D, Nofroni C, Comanducci M, Riley DR, Daugherty SC, Angiuoli SV, et al. Neisseria meningitidis is structured in clades associated with restriction modification systems that modulate homologous recombination. Proc Natl Acad Sci U S A. 2011;108(11):4494-9.

28. Joseph B, Schwarz RF, Linke B, Blom J, Becker A, Claus H, Goesmann A, Frosch M, Muller T, Vogel $U$, et al. Virulence evolution of the human pathogen Neisseria meningitidis by recombination in the core and accessory genome. PLoS One. 2011;6(4):e18441. 
29. Grifantini R, Frigimelica E, Delany I, Bartolini E, Giovinazzi S, Balloni S, Agarwal S, Galli G, Genco C, Grandi G. Characterization of a novel Neisseria meningitidis Fur and iron-regulated operon required for protection from oxidative stress: utility of DNA microarray in the assignment of the biological role of hypothetical genes. Mol Microbiol. 2004;54(4):962-79.

30. Grifantini R, Sebastian S, Frigimelica E, Draghi M, Bartolini E, Muzzi A, Rappuoli R, Grandi G, Genco CA. Identification of iron-activated and -repressed Fur-dependent genes by transcriptome analysis of Neisseria meningitidis group B. Proc Natl Acad Sci U S A. 2003;100(16):9542-7.

31. Guckenberger M, Kurz S, Aepinus C, Theiss S, Haller S, Leimbach T, Panzner U, Weber J, Paul H, Unkmeir A, et al. Analysis of the heat shock response of Neisseria meningitidis with cDNA- and oligonucleotide-based DNA microarrays. J Bacteriol. 2002;184(9):2546-51.

32. Bartolini E, Frigimelica E, Giovinazzi S, Galli G, Shaik Y, Genco C, Welsch JA, Granoff DM, Grandi G, Grifantini R. Role of FNR and FNR-regulated, sugar fermentation genes in Neisseria meningitidis infection. Mol Microbiol. 2006; 60(4):963-72.

33. Newcombe J, Jeynes JC, Mendoza E, Hinds J, Marsden GL, Stabler RA, Marti $\mathrm{M}, \mathrm{McFadden} \mathrm{JJ.} \mathrm{Phenotypic} \mathrm{and} \mathrm{transcriptional} \mathrm{characterization} \mathrm{of} \mathrm{the}$ meningococcal PhoPQ system, a magnesium-sensing two-component regulatory system that controls genes involved in remodeling the meningococcal cell surface. J Bacteriol. 2005;187(14):4967-75.

34. Tzeng YL, Kahler CM, Zhang X, Stephens DS. MisR/MisS two-component regulon in Neisseria meningitidis. Infect Immun. 2008;76(2):704-16.

35. Chandler $\mathrm{CH}$, Chari S, Dworkin I. Does your gene need a background check? How genetic background impacts the analysis of mutations, genes, and evolution. Trends Genet. 2013;29:358-66.

36. Paaby AB, Rockman MV. Cryptic genetic variation: evolution's hidden substrate. Nat Rev Genet. 2014;15(4):247-58.

37. Galperin MY, Makarova KS, Wolf YI, Koonin EV. Expanded microbial genome coverage and improved protein family annotation in the COG database. Nucleic Acids Res. 2015;43(Database issue):D261-9.

38. Criss AK, Seifert HS. A bacterial siren song: intimate interactions between Neisseria and neutrophils. Nat Rev Microbiol. 2012;10(3):178-90.

39. Schoen C, Claus H, Vogel U, Frosch M. Genomes of pathogenic Neisseria species. In: Hacker J, Dobrindt U, editors. Pathogenomics. Weinheim: Wiley-VCH; 2006. p. 231-55.

40. Snyder LA, Saunders NJ. The majority of genes in the pathogenic Neisseria species are present in non-pathogenic Neisseria lactamica, including those designated as virulence genes. BMC Genomics. 2006;7(1):128.

41. Schmitt C, Turner D, Boesl M, Abele M, Frosch M, Kurzai O. A functional two-partner secretion system contributes to adhesion of Neisseria meningitidis to epithelial cells. J Bacteriol. 2007;189(22):7968-76.

42. Osicka R, Kalmusova J, Krizova P, Sebo P. Neisseria meningitidis RTX protein FrpC induces high levels of serum antibodies during invasive disease: polymorphism of frpC alleles and purification of recombinant FrpC. Infect Immun. 2001;69(9):5509-19.

43. Capecchi B, Adu-Bobie J, Di Marcello F, Ciucchi L, Masignani V, Taddei A, Rappuoli R, Pizza M, Arico B. Neisseria meningitidis NadA is a new invasin which promotes bacterial adhesion to and penetration into human epithelial cells. Mol Microbiol. 2005;55(3):687-98.

44. Schenkels LC, Veerman EC, Nieuw Amerongen AV. Biochemical composition of human saliva in relation to other mucosal fluids. Crit Rev Oral Biol Med. 1995;6(2):161-75.

45. Sim RJ, Harrison MM, Moxon ER, Tang CM. Underestimation of meningococci in tonsillar tissue by nasopharyngeal swabbing. Lancet. 2000;356(9242): 1653-4.

46. Yi K, Rasmussen AW, Gudlavalleti SK, Stephens DS, Stojiljkovic I. Biofilm formation by Neisseria meningitidis. Infect Immun. 2004;72(10):6132-8

47. Kostakioti M, Hadjifrangiskou M, Hultgren SJ. Bacterial biofilms: development, dispersal, and therapeutic strategies in the dawn of the postantibiotic era. Cold Spring Harbor Perspect Med. 2013;3(4): a010306.

48. Hellerud BC, Olstad OK, Nielsen EW, Troseid AM, Skadberg O, Thorgersen EB, Vege A, Mollnes TE, Brandtzaeg P. Massive organ inflammation in experimental and in clinical meningococcal septic shock. Shock (Augusta, Ga). 2015;44(5):458-69.

49. Virji M. Pathogenic neisseriae: surface modulation, pathogenesis and infection control. Nat Rev Microbiol. 2009;7(4):274-86.

50. Anjum MF, Stevanin TM, Read RC, Moir JW. Nitric oxide metabolism in Neisseria meningitidis. J Bacteriol. 2002;184(11):2987-93.
51. Kobsar A, Siauw C, Gambaryan S, Hebling S, Speer C, Schubert-Unkmeir A, Eigenthaler M. Neisseria meningitidis induces platelet inhibition and increases vascular endothelial permeability via nitric oxide regulated pathways. Thromb Haemost. 2011;106(6):1127-38.

52. Stevanin TM, Laver JR, Poole RK, Moir JW, Read RC. Metabolism of nitric oxide by Neisseria meningitidis modifies release of NO-regulated cytokines and chemokines by human macrophages. Microbes Infection/Institut Pasteur. 2007;9(8):981-7.

53. Dittrich MT, Klau GW, Rosenwald A, Dandekar T, Muller T. Identifying functional modules in protein-protein interaction networks: an integrated exact approach. Bioinformatics (Oxford, England). 2008; 24(13):i223-31.

54. Franceschini A, Szklarczyk D, Frankild S, Kuhn M, Simonovic M, Roth A, Lin J, Minguez P, Bork P, von Mering C, et al. STRING v9.1: protein-protein interaction networks, with increased coverage and integration. Nucleic Acids Res. 2013;41(Database issue):D808-15.

55. Mendum TA, Newcombe J, Mannan AA, Kierzek AM, McFadden J. Interrogation of global mutagenesis data with a genome scale model of Neisseria meningitidis to assess gene fitness in vitro and in sera. Genome Biol. 2011;12(12):R127.

56. Schwarz R, Liang C, Kaleta C, Kuhnel M, Hoffmann E, Kuznetsov S, Hecker M, Griffiths G, Schuster S, Dandekar T. Integrated network reconstruction, visualization and analysis using YANAsquare. BMC Bioinformatics. 2007:8:313.

57. Liang C, Liebeke M, Schwarz R, Zuhlke D, Fuchs S, Menschner L, Engelmann S, Wolz C, Jaglitz S, Bernhardt J, et al. Staphylococcus aureus physiological growth limitations: insights from flux calculations built on proteomics and external metabolite data. Proteomics. 2011;11(10):1915-35.

58. Lentner C. Geigy scientific tables, Units of measurement, body fluids, composition of the body, nutrition. 8th ed. Basle: CIBA-GEIGY; 1981.

59. Smith $H$, Tang CM, Exley RM. Effect of host lactate on gonococci and meningococci: new concepts on the role of metabolites in pathogenicity. Infect Immun. 2007;75(9):4190-8.

60. Catlin BW. Nutritional profiles of Neisseria gonorrhoeae, Neisseria meningitidis, and Neisseria lactamica in chemically defined media and the use of growth requirements for gonococcal typing. J Infect Dis. 1973;128(2): 178-94.

61. Rusniok C, Vallenet D, Floquet S, Ewles H, Mouze-Soulama C, Brown D, Lajus A, Buchrieser C, Medigue C, Glaser P, et al. NeMeSys: a biological resource for narrowing the gap between sequence and function in the human pathogen Neisseria meningitidis. Genome Biol. 2009;10(10):R110.

62. van Heeswijk WC, Westerhoff HV, Boogerd FC. Nitrogen assimilation in Escherichia coli: putting molecular data into a systems perspective. Microbiol Mol Biol Rev. 2013;77(4):628-95.

63. Saunders NJ, Snyder LA. The minimal mobile element. Microbiology (Reading, England). 2002;148(Pt 12):3756-60.

64. Snyder LA, McGowan S, Rogers M, Duro E, O'Farrell E, Saunders NJ. The repertoire of minimal mobile elements in the Neisseria species and evidence that these are involved in horizontal gene transfer in other bacteria. Mol Biol Evol. 2007;24(12):2802-15.

65. Buisine N, Tang CM, Chalmers R. Transposon-like Correia elements: structure, distribution and genetic exchange between pathogenic Neisseria sp. FEBS Lett. 2002;522(1-3):52-8.

66. Siddique A, Buisine N, Chalmers R. The transposon-like Correia elements encode numerous strong promoters and provide a potential new mechanism for phase variation in the meningococcus. PLoS Genet. 2011; 7(1):e1001277.

67. Snyder LA, Cole JA, Pallen MJ. Comparative analysis of two Neisseria gonorrhoeae genome sequences reveals evidence of mobilization of Correia repeat enclosed elements and their role in regulation. BMC Genomics. 2009;10:70.

68. Jamet A, Rousseau C, Monfort JB, Frapy E, Nassif X, Martin P. A twocomponent system is required for colonization of host cells by meningococcus. Microbiology (Reading, England). 2009;155(Pt 7):2288-95.

69. Newcombe J, Eales-Reynolds LJ, Wootton L, Gorringe AR, Funnell SG, Taylor SC, MCFadden JJ. Infection with an avirulent phoP mutant of Neisseria meningitidis confers broad cross-reactive immunity. Infect Immun. 2004; 72(1):338-44.

70. Delany I, Grifantini R, Bartolini E, Rappuoli R, Scarlato V. Effect of Neisseria meningitidis fur mutations on global control of gene transcription. J Bacteriol. 2006;188(7):2483-92. 
71. Gunesekere IC, Kahler CM, Ryan CS, Snyder LA, Saunders NJ, Rood JI, Davies JK. Ecf, an alternative sigma factor from Neisseria gonorrhoeae, controls expression of msrAB, which encodes methionine sulfoxide reductase. J Bacteriol. 2006;188(10):3463-9.

72. Veld RA H i't, Willemsen AM, van Kampen AH, Bradley EJ, Baas F, Pannekoek $Y$, van der Ende A. Deep sequencing whole transcriptome exploration of the sigmaE regulon in Neisseria meningitidis. PLoS One. 2011;6(12):e29002.

73. Beisel CL, Storz G. Base pairing small RNAs and their roles in global regulatory networks. FEMS Microbiol Rev. 2010;34(5):866-82.

74. Fantappie L, Metruccio MM, Seib KL, Oriente F, Cartocci E, Ferlicca F, Giuliani MM, Scarlato V, Delany I. The RNA chaperone Hfq is involved in stress response and virulence in Neisseria meningitidis and is a pleiotropic regulator of protein expression. Infect Immun. 2009;77(5):1842-53.

75. Remmele CW, Xian Y, Albrecht M, Faulstich M, Fraunholz M, Heinrichs E, Dittrich MT, Muller T, Reinhardt R, Rudel T. Transcriptional landscape and essential genes of Neisseria gonorrhoeae. Nucleic Acids Res. 2014;42(16): 10579-95.

76. Dalebroux ZD, Svensson SL, Gaynor EC, Swanson MS. ppGpp conjures bacterial virulence. Microbiol Mol Biol Rev. 2010;74(2):171-99.

77. Zuo Y, Wang Y, Steitz TA. The mechanism of E. coli RNA polymerase regulation by ppGpp is suggested by the structure of their complex. Mol Cell. 2013;50(3):430-6.

78. Ross W, Vrentas CE, Sanchez-Vazquez P, Gaal T, Gourse RL. The magic spot: a ppGpp binding site on E. coli RNA polymerase responsible for regulation of transcription initiation. Mol Cell. 2013;50(3):420-9.

79. Delihas N. Impact of small repeat sequences on bacterial genome evolution. Genome Biol Evol. 2011;3:959-73.

80. Abu Kwaik Y, Bumann D. Microbial quest for food in vivo: 'nutritional virulence' as an emerging paradigm. Cell Microbiol. 2013;15(6):882-90.

81. Brown SA, Palmer KL, Whiteley M. Revisiting the host as a growth medium. Nat Rev Microbiol. 2008;6(9):657-66.

82. Lo H, Tang CM, Exley RM. Mechanisms of avoidance of host immunity by Neisseria meningitidis and its effect on vaccine development. Lancet Infect Dis. 2009;9(7):418-27.

83. Schmitt C, Villwock A, Kurzai O. Recognition of meningococcal molecular patterns by innate immune receptors. Int J Med Microbiol. 2009;299(1):9-20.

84. Seib KL, Wu HJ, Kidd SP, Apicella MA, Jennings MP, McEwan AG. Defenses against oxidative stress in Neisseria gonorrhoeae: a system tailored for a challenging environment. Microbiol Mol Biol Rev. 2006;70(2):344-61.

85. Baart G, Zomer B, de Haan A, van der Pol L, Beuvery EC, Tramper J, Martens D. Modeling Neisseria meningitidis metabolism: from genome to metabolic fluxes. Genome Biol. 2007;8(7):R136.

86. Tala A, Monaco C, Nagorska K, Exley RM, Corbett A, Zychlinsky A, Alifano P Tang CM. Glutamate utilization promotes meningococcal survival in vivo through avoidance of the neutrophil oxidative burst. Mol Microbiol. 2011; 81(5):1330-42.

87. Monaco C, Tala A, Spinosa MR, Progida C, De Nitto E, Gaballo A, Bruni CB, Bucci C, Alifano P. Identification of a meningococcal L-glutamate ABC transporter operon essential for growth in low-sodium environments. Infect Immun. 2006;74(3):1725-40.

88. Casadevall A, Pirofski LA. The damage-response framework of microbial pathogenesis. Nat Rev Microbiol. 2003;1(1):17-24.

89. Shlomi T, Eisenberg Y, Sharan R, Ruppin E. A genome-scale computational study of the interplay between transcriptional regulation and metabolism. Mol Syst Biol. 2007;3:101.

90. Kochanowski K, Sauer U, Chubukov V. Somewhat in control-the role of transcription in regulating microbial metabolic fluxes. Curr Opin Biotechnol. 2013;24(6):987-93.

91. Del Tordello E, Bottini S, Muzzi A, Serruto D. Analysis of the regulated transcriptome of Neisseria meningitidis in human blood using a tiling array. J Bacteriol. 2012;194(22):6217-32.

92. Callaghan MJ, Buckee CO, Jolley KA, Kriz P, Maiden MC, Gupta S. The effect of immune selection on the structure of the meningococcal opa protein repertoire. PLoS Pathog. 2008;4(3):e1000020.

93. Comanducci M, Bambini S, Caugant DA, Mora M, Brunelli B, Capecchi B, Ciucchi L, Rappuoli R, Pizza M. NadA diversity and carriage in Neisseria meningitidis. Infect Immun. 2004;72(7):4217-23.

94. Jolley KA, Kalmusova J, Feil EJ, Gupta S, Musilek M, Kriz P, Maiden MC. Carried meningococci in the Czech Republic: a diverse recombining population. J Clin Microbiol. 2000;38(12):4492-8.
95. Maiden MC, Bygraves JA, Feil E, Morelli G, Russell JE, Urwin R, Zhang Q, Zhou J, Zurth K, Caugant DA, et al. Multilocus sequence typing: a portable approach to the identification of clones within populations of pathogenic microorganisms. Proc Natl Acad Sci U S A. 1998;95(6): 3140-5.

96. Dewhirst FE, Chen T, Izard J, Paster BJ, Tanner AC, Yu WH, Lakshmanan A, Wade WG. The human oral microbiome. J Bacteriol. 2010;192(19):5002-17.

97. Barquist $L$, Vogel J. Accelerating discovery and functional analysis of small RNAs with new technologies. Annu Rev Genet. 2015;49:367-94.

98. Agarwal A, Koppstein D, Rozowsky J, Sboner A, Habegger L, Hillier LW, Sasidharan R, Reinke V, Waterston RH, Gerstein M. Comparison and calibration of transcriptome data from RNA-Seq and tiling arrays. BMC Genomics. 2010;11:383.

99. Wexselblatt E, Oppenheimer-Shaanan Y, Kaspy I, London N, SchuelerFurman O, Yavin E, Glaser G, Katzhendler J, Ben-Yehuda S. Relacin, a novel antibacterial agent targeting the stringent response. PLoS Pathog. 2012;8(9): e1002925.

100. Claus H, Maiden MC, Wilson DJ, McCarthy ND, Jolley KA, Urwin R, Hessler F, Frosch M, Vogel U. Genetic analysis of meningococci carried by children and young adults. J Infect Dis. 2005;191(8):1263-71.

101. McGuinness BT, Clarke IN, Lambden PR, Barlow AK, Poolman JT, Jones DM, Heckels JE. Point mutation in meningococcal por A gene associated with increased endemic disease. Lancet. 1991;337(8740):514-7.

102. Lappann M, Haagensen JA, Claus H, Vogel U, Molin S. Meningococcal biofilm formation: structure, development and phenotypes in a standardized continuous flow system. Mol Microbiol. 2006;62(5):1292-309.

103. Kurzai O, Schmitt C, Claus H, Vogel U, Frosch M, Kolb-Maurer A. Carbohydrate composition of meningococcal lipopolysaccharide modulates the interaction of Neisseria meningitidis with human dendritic cells. Cell Microbiol. 2005;7(9):1319-34.

104. Vogel U, Weinberger A, Frank R, Muller A, Kohl J, Atkinson JP, Frosch M. Complement factor $\mathrm{C} 3$ deposition and serum resistance in isogenic capsule and lipooligosaccharide sialic acid mutants of serogroup B Neisseria meningitidis. Infect Immun. 1997;65(10):4022-9.

105. Rissman Al, Mau B, Biehl BS, Darling AE, Glasner JD, Perna NT. Reordering contigs of draft genomes using the Mauve aligner. Bioinformatics (Oxford, England). 2009;25(16):2071-3.

106. Meyer F, Goesmann A, McHardy AC, Bartels D, Bekel T, Clausen J, Kalinowski J, Linke B, Rupp O, Giegerich R, et al. GenDB-an open source genome annotation system for prokaryote genomes. Nucleic Acids Res. 2003;31(8): 2187-95.

107. Darling AC, Mau B, Blattner FR, Perna NT. Mauve: multiple alignment of conserved genomic sequence with rearrangements. Genome Res. 2004; 14(7):1394-403.

108. Carver TJ, Rutherford KM, Berriman M, Rajandream MA, Barrell BG, Parkhill J. ACT: the Artemis comparison tool. Bioinformatics (Oxford, England). 2005; 21(16):3422-3.

109. Altschul SF, Madden TL, Schaffer AA, Zhang J, Zhang Z, Miller W, Lipman DJ. Gapped BLAST and PSI-BLAST: a new generation of protein database search programs. Nucleic Acids Res. 1997;25(17):3389-402.

110. Lerat $E$, Daubin V, Moran NA. From gene trees to organismal phylogeny in prokaryotes: the case of the gamma-Proteobacteria. PLoS Biol. 2003;1(1):E19.

111. Marchler-Bauer A, Derbyshire MK, Gonzales NR, Lu S, Chitsaz F, Geer LY, Geer RC, He J, Gwadz M, Hurwitz DI, et al. CDD: NCBl's conserved domain database. Nucleic Acids Res. 2015;43(Database issue):D222-6.

112. Yu NY, Wagner JR, Laird MR, Melli G, Rey S, Lo R, Dao P, Sahinalp SC, Ester M, Foster LJ, et al. PSORTb 3.0: improved protein subcellular localization prediction with refined localization subcategories and predictive capabilities for all prokaryotes. Bioinformatics (Oxford, England). 2010;26(13):1608-15.

113. Bailey TL, Boden M, Buske FA, Frith M, Grant CE, Clementi L, Ren J, Li WW, Noble WS. MEME SUITE: tools for motif discovery and searching. Nucleic Acids Res. 2009;37(Web Server issue):W202-8.

114. Rice P, Longden I, Bleasby A. EMBOSS: the European molecular biology open software suite. Trends Genet. 2000;16(6):276-7.

115. Parkhill J, Achtman M, James KD, Bentley SD, Churcher C, Klee SR, Morelli G, Basham D, Brown D, Chillingworth T, et al. Complete DNA sequence of a serogroup A strain of Neisseria meningitidis Z2491. Nature. 2000;404(6777): 502-6.

116. Edgar RC. MUSCLE: multiple sequence alignment with high accuracy and high throughput. Nucleic Acids Res. 2004;32(5):1792-7. 
117. Reese MG. Application of a time-delay neural network to promoter annotation in the Drosophila melanogaster genome. Comput Chem. 2001; 26(1):51-6.

118. Schwarz R, Joseph B, Gerlach G, Schramm-Gluck A, Engelhard K, Frosch M, Muller T, Schoen C. Evaluation of one- and two-color gene expression arrays for microbial comparative genome hybridization analyses in routine applications. J Clin Microbiol. 2010;48(9):3105-10.

119. R Core Team. R: a language and environment for statistical computing. Vienna: R Foundation for Statistical Computing; 2014.

120. Smyth GK. Limma: linear models for microarray data. In: Gentleman R, Carey V, Dudoit SR, Irizarry R, Huber W, editors. Bioinformatics and computational biology solutions using $\mathrm{R}$ and bioconductor. New York: Springer Science + Business Media, Inc; 2005. p. 397-420.

121. Beisser D, Klau GW, Dandekar T, Muller T, Dittrich MT. BioNet: an R-package for the functional analysis of biological networks. Bioinformatics (Oxford, England). 2010;26(8):1129-30.

122. Joseph B, Schneiker-Bekel S, Schramm-Gluck A, Blom J, Claus H, Linke B, Schwarz RF, Becker A, Goesmann A, Frosch M, et al. Comparative genome biology of a serogroup B carriage and disease strain supports a polygenic nature of meningococcal virulence. J Bacteriol. 2010;192(20):5363-77.

123. Tettelin H, Saunders NJ, Heidelberg J, Jeffries AC, Nelson KE, Eisen JA, Ketchum KA, Hood DW, Peden JF, Dodson RJ, et al. Complete genome sequence of Neisseria meningitidis serogroup B strain MC58. Science (New York, NY). 2000;287(5459):1809-15.

124. Takahashi H, Yanagisawa T, Kim KS, Yokoyama S, Ohnishi M. Multiple functions of glutamate uptake via meningococcal GItT-GltM I-glutamate $A B C$ transporter in Neisseria meningitidis internalization into human brain microvascular endothelial cells. Infect Immun. 2015;83(9):3555-67.

125. Coureuil M, Bourdoulous S, Marullo S, Nassif X. Invasive meningococcal disease: a disease of the endothelial cells. Trends Mol Med. 2014;20(10): $571-8$.

\section{Submit your next manuscript to BioMed Central} and we will help you at every step:

- We accept pre-submission inquiries

- Our selector tool helps you to find the most relevant journal

- We provide round the clock customer support

- Convenient online submission

- Thorough peer review

- Inclusion in PubMed and all major indexing services

- Maximum visibility for your research

Submit your manuscript at www.biomedcentral.com/submit 